\title{
O bolso ou a ideologia? Determinantes da opinião dos brasileiros sobre globalização e livre comércio
}

\author{
Flávio Pinheiro ${ }^{1}($ i) \\ Ivan Filipe Fernandes ${ }^{2}$ \\ Maria Herminia Tavares de Almeida ${ }^{3}$
}

\begin{abstract}
O artigo discute os determinantes das opiniões dos brasileiros sobre a integração da economia brasileira aos mercados globais, analisando dados de survey nacional, realizado no âmbito do projeto "O Brasil, as Américas e o mundo". Mostramos que os brasileiros, em boa medida, são favoráveis à abertura internacional de nossa economia e que suas atitudes são guiadas tanto por motivações econômicas como por ideias e valores políticos. A baixa exposição da economia brasileira à concorrência externa parece contribuir para a existência de opiniões favoráveis a maior acesso a bens importados. A posição ideológica, por sua vez, age como um filtro dessas percepções independentemente das condições econômicas dos indivíduos. Assim, evidências indicam que a posição do indivíduo como consumidor, sua ideologia política e suas visões nacionalistas influem em suas opiniões sobre globalização e livre comércio. Os resultados confirmam estudos anteriores sobre o mesmo tema feitos em países em desenvolvimento.
\end{abstract}

Palavras-chave: opinião pública; comportamento político; globalização; comércio internacional; economia política internacional

\section{Introdução ${ }^{4}$}

O propósito deste artigo é descrever e explicar as opiniões, em geral positivas, do público brasileiro sobre a globalização e o livre comércio. O que pensam os brasileiros sobre a integração da economia nacional aos mercados globais? Quais são as suas atitudes em relação à globalização econômica e ao livre comércio e que fatores determinam suas visões?

No século XX, o Brasil se desenvolveu com políticas de substituição de importações que mantiveram a economia bastante protegida. A abertura econômica e as chamadas

\footnotetext{
1 Universidade Federal do ABC, Departamento de Políticas Públicas. Santo André (SP), Brasil. E-mail: <pinheiro.f@ufabc.edu.br>.

2 Universidade Federal do ABC, Departamento de Políticas Públicas. Santo André (SP), Brasil.

E-mail: <ivan.fernandes@ufabc.edu.br>.

3 Centro Brasileiro de Análise e Planejamento (Cebrap). São Paulo (SP), Brasil.

E-mail: <mhbtdalm@usp.br>.

${ }^{4}$ Este artigo traz resultados parciais do Projeto Temático Fapesp 2010/06356-3, 2013/00445-4 e 2018/.006461. Versões preliminares foram apresentadas em painéis nas reuniões da Red de Economía Política de América Latina - Repal (2017), em Bogotá, e da Latin American Studies Association - Lasa (2018), em Boston, e se beneficiaram dos comentários dos participantes. Os autores agradecem os comentários e as preciosas sugestões de Leandro Piquet Carneiro sobre o modelo estatístico utilizado.
} 
reformas de mercado dos anos 1990 foram moderadas e asseguraram a permanência de proteção a setores industriais relevantes, pela via de tarifas ou subsídios. E a discussão sobre liberalização versus protecionismo continua a dividir as lideranças políticas, empresariais e sociais, sem vencedor claro. Paradoxalmente, a maioria significativa dos brasileiros aprova a liberalização comercial e a globalização, essa última entendida como maior contato da economia nacional com outras economias do mundo, mesmo quando apresentada a algumas de suas consequências negativas. A porcentagem dos que declaram apoio à globalização no país é significativa também se comparada a de outros públicos latino-americanos.

Utilizamos dados do projeto "Brasil, as Américas e o mundo"5 (Almeida et al., 2014) para entrar nesse debate. Nossa tese é que as opiniões dos indivíduos sobre livre comércio e abertura econômica são determinadas em grande parte por sua postura como consumidor mais ou menos propenso a adquirir produtos importados, por sua ideologia política e por seu grau de nacionalismo. Nossos resultados reforçam achados da literatura de economia política internacional sobre países em desenvolvimento, mas ainda pouco explorados para o caso brasileiro e pela literatura nacional.

Optamos por utilizar duas medidas para avaliar as atitudes dos brasileiros em relação àqueles fenômenos. A primeira capta a percepção do impacto imediato da liberalização comercial e da globalização sobre a vida do próprio respondente, enquanto a segunda mede o apoio ou a reprovação à globalização econômica e ao livre comércio em termos mais amplos e multidimensionais, em razão do efeito percebido desses fenômenos sobre as empresas nacionais, a economia do país, a geração de empregos, a estabilidade no trabalho, a agricultura, o meio ambiente e as gerações futuras.

O artigo está dividido em quatro partes, além desta introdução. Na primeira, "O que pensam os brasileiros?", apresentamos as informações que encontramos para o Brasil. $\mathrm{Na}$ segunda seção, "Opinião pública, globalização e livre comércio", revemos as explicações correntes na literatura, concedendo especial atenção aos estudos sobre países em desenvolvimento, em particular aos latino-americanos. Na terceira, "Explicando as opiniões dos brasileiros: o modelo", descrevemos a estratégia de análise empírica, a definição das variáveis de maior interesse e os resultados da análise dos determinantes das preferências brasileiras em relação à integração da economia nacional aos mercados globais. Na última seção, apresentamos a "Conclusão".

\section{0 que pensam os brasileiros?}

Os brasileiros têm, de um modo geral, opinião positiva sobre os efeitos da globalização, ainda que a proporção dos que a apoiam varie segundo seu interesse e a

\footnotetext{
5 Pesquisa de opinião pública realizada em novembro de 2014 com amostra probabilística, com distribuição nacional estratificada, com 1.881 entrevistados e margem de erro de 2,3\%. O trabalho foi coordenado pelo Centro Brasileiro de Análise e Planejamento (Cebrap) e contou com o apoio da Fundação de Amparo à Pesquisa do Estado de São Paulo (Fapesp). Disponível em: <https://cebrap.org.br/wpcontent/uploads/2017/09/Brasil_Ame\%CC\%81ricas\%E2\%80\%93mundo.pdf>. Acesso em: 1 jan. 2020.
} 
informação sobre questões internacionais. Para captar essa diferença, dividimos os respondentes de nossa amostra em duas categorias: Público Interessado e Informado (PII) e, o seu contrário, Público Desinteressado e Desinformado (PDD). Analisamos as atitudes dos entrevistados em relação aos efeitos do fenômeno sobre diversas dimensões: economia brasileira, gerações futuras, empresas brasileiras, padrão de vida do entrevistado, geração de empregos, estabilidade no trabalho e meio ambiente. Os resultados estão no Gráfico 1:

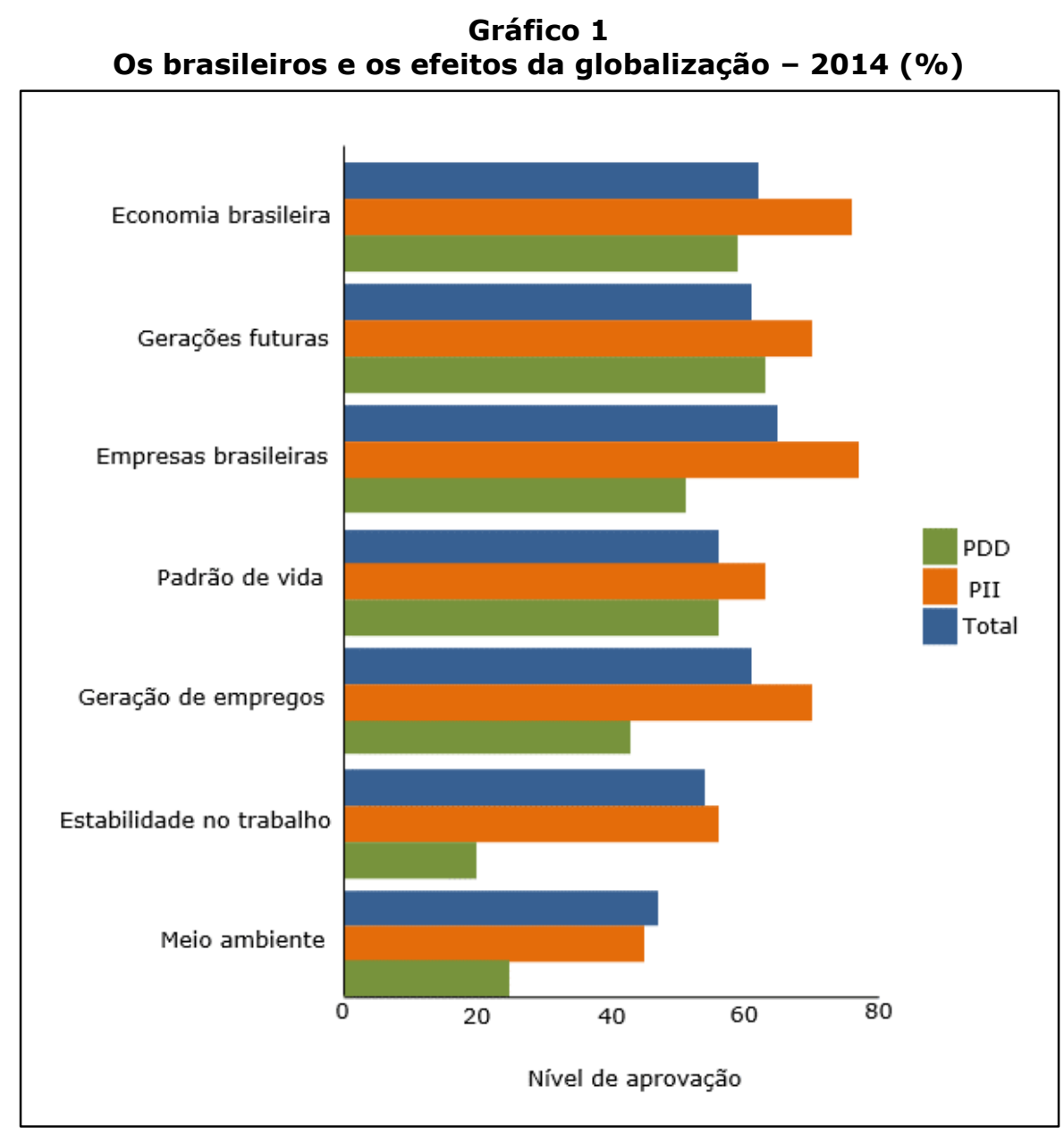

Fonte: Elaboração própria com base em dados do projeto "Brasil, as Américas e o mundo" (Almeida et al., 2014). Pergunta: O(a) sr.(a) acha que a globalização é algo muito ruim, ruim, nem bom nem ruim, bom ou muito bom para (...)? Notar que o nível de aprovação é a soma das respostas "bom e muito bom".

Para parcela significativa do público brasileiro, os efeitos da globalização são sempre positivos, exceção feita a seu impacto no meio ambiente. A parcela do público interessada e relativamente informada é sistematicamente mais otimista. Esse resultado não surpreende: ele se repete em pesquisas semelhantes feitas em outros países. Pessoas pouco informadas 
e pouco interessadas por questões internacionais tendem a ser mais paroquiais e mais reticentes e desconfiadas dos efeitos domésticos dos processos globais.

Encontramos o mesmo padrão de respostas à pergunta sobre as consequências do livre comércio, como é possível observar no Gráfico 2:

\section{Gráfico 2}

Os brasileiros e os efeitos do livre comércio - $2014(\%)$

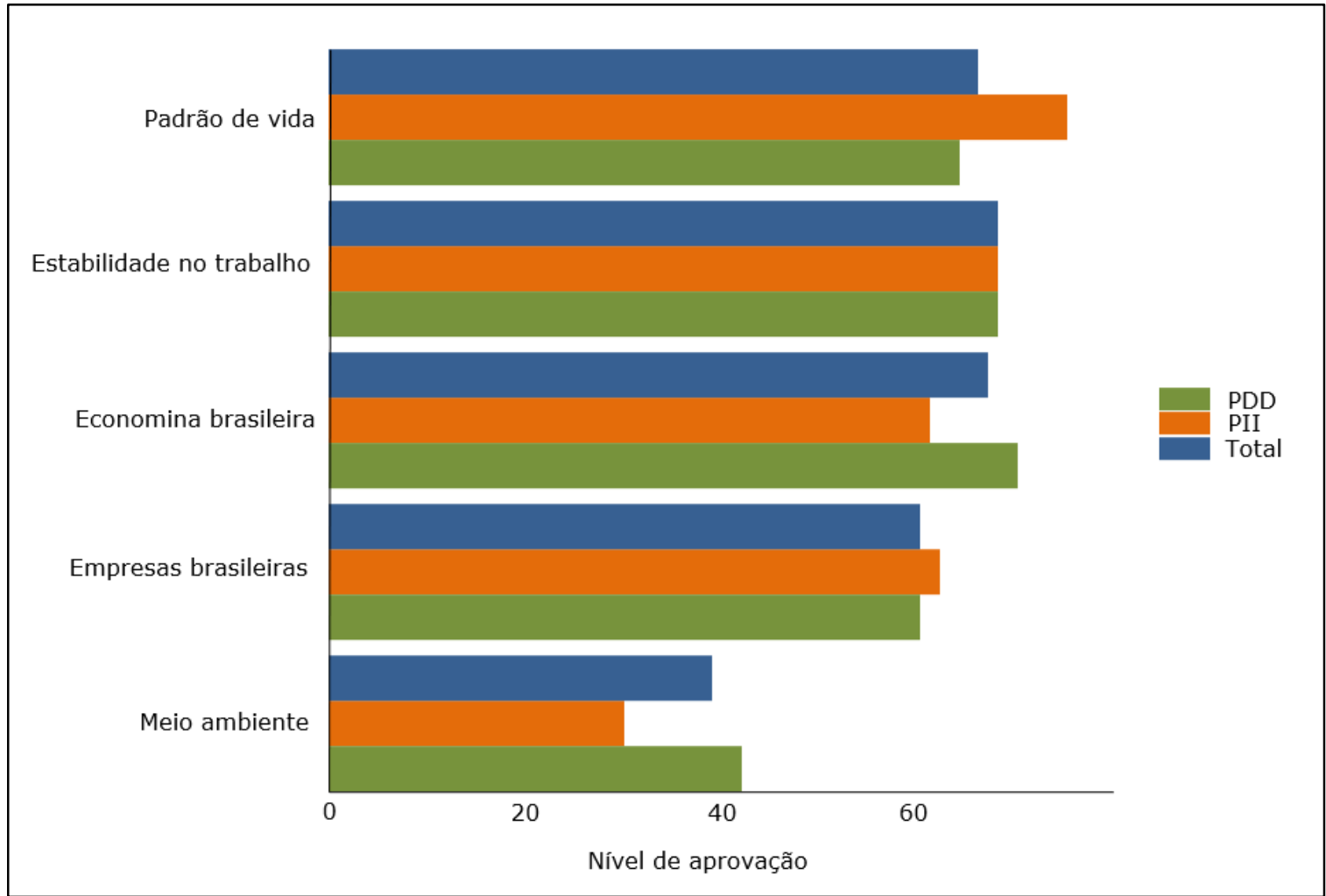

Fonte: Elaboração própria com base em dados do projeto "Brasil, as Américas e o Mundo" (Almeida et al., 2014). Nota: Pergunta: $O($ (a) sr.(a) acha que livre comercio é algo muito ruim, ruim, nem bom nem ruim, bom ou muito bom para (...). Notar que o nível de aprovação é a soma das respostas "bom e muito bom".

É patente a existência de um apoio majoritário à integração da economia nacional ao mercado internacional. Em cinco dos seis temas, mais de $60 \%$ da população entende que a liberalização comercial é positiva para o Brasil. Mesmo quando a pergunta se refere às consequências do livre comércio para o trabalho e o padrão de vida do respondente, o apoio é de impactantes $68 \%$ e $67 \%$, respectivamente. Os entrevistados percebem consequências negativas apenas quando se trata do meio ambiente. Percebe-se maior convergência de opiniões entre os dois grupos de entrevistados na discussão sobre livre comércio do que o observado quando o assunto é globalização.

As atitudes favoráveis à abertura econômica ao exterior são confirmadas por 
respostas a duas outras perguntas que dizem respeito ao efeito dos investimentos estrangeiros e à redução de barreiras à entrada de produtos estrangeiros. Os dados estão nos Gráficos 3 e 4 . Encontramos novamente um apoio importante dos brasileiros à abertura da economia ao exterior. Cerca de $58 \%$ dos respondentes são favoráveis à redução de barreiras comerciais, não havendo diferença significativa entre PII e PDD (Gráfico 3).

Por outro lado, parcela majoritária do PII acha que a atração de investimentos estrangeiros é benéfica ao país (Gráfico 4). Encontramos maior resistência entre os membros do $P D D$ : apenas $33,7 \%$ dos entrevistados consideram positiva a atração de investimentos estrangeiros.

Gráfico 3

Nível de aprovação popular sobre redução de barreiras a produtos estrangeiros - 2014 (\%)

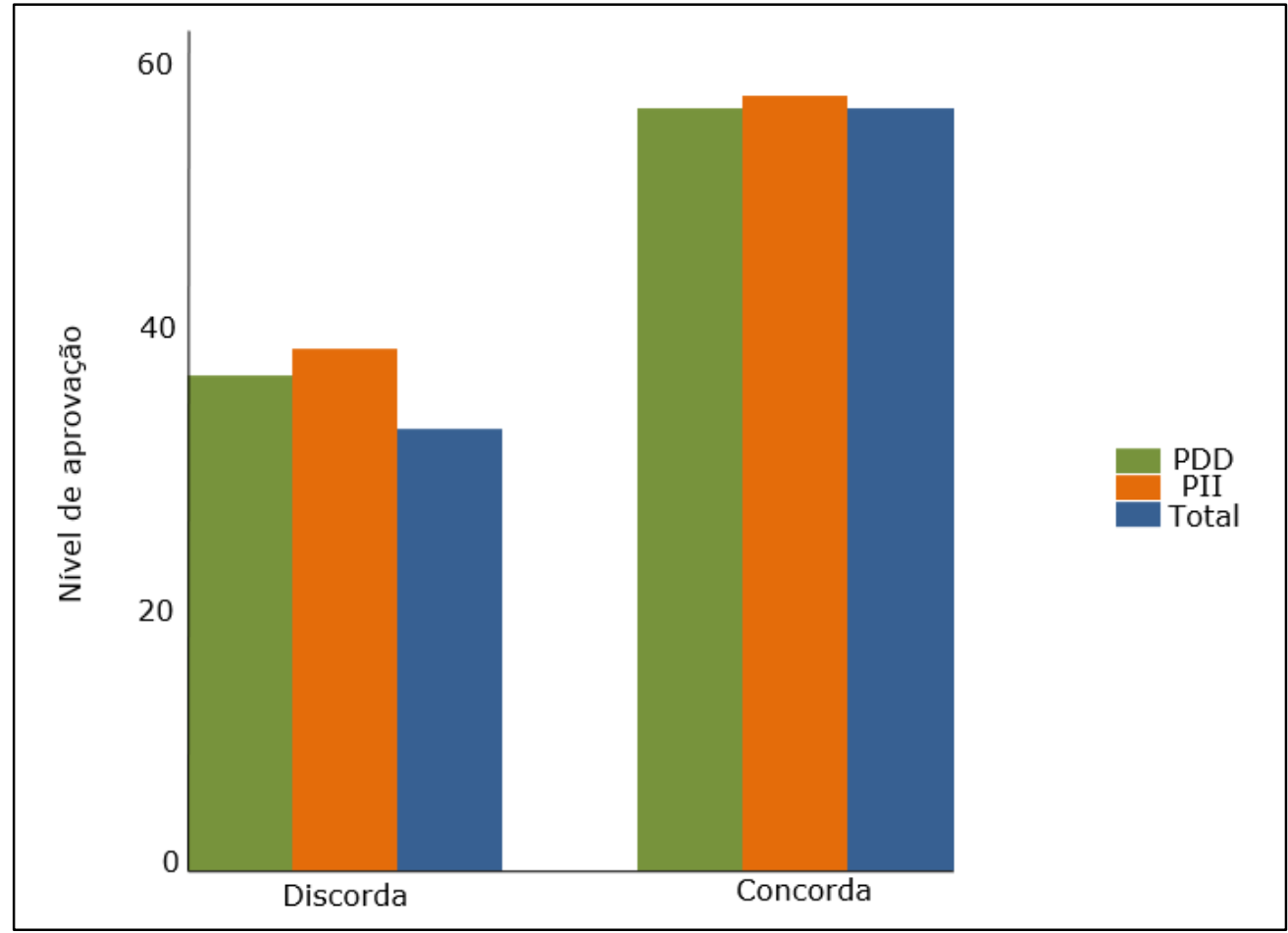

Fonte: Elaboração própria com base em dados do projeto "Brasil, as Américas e o mundo" (Almeida et al., 2014).

Nota: Pergunta - Você concordaria ou não se o Brasil reduzisse as barreiras de entrada de produtos estrangeiros? Concordaria muito/Concordaria um pouco/Discordaria um pouco/Discordaria muito/NS/NR. 


\section{Gráfico 4 \\ Nível de aprovação popular sobre atração de investimentos externos - 2014 (\%)}

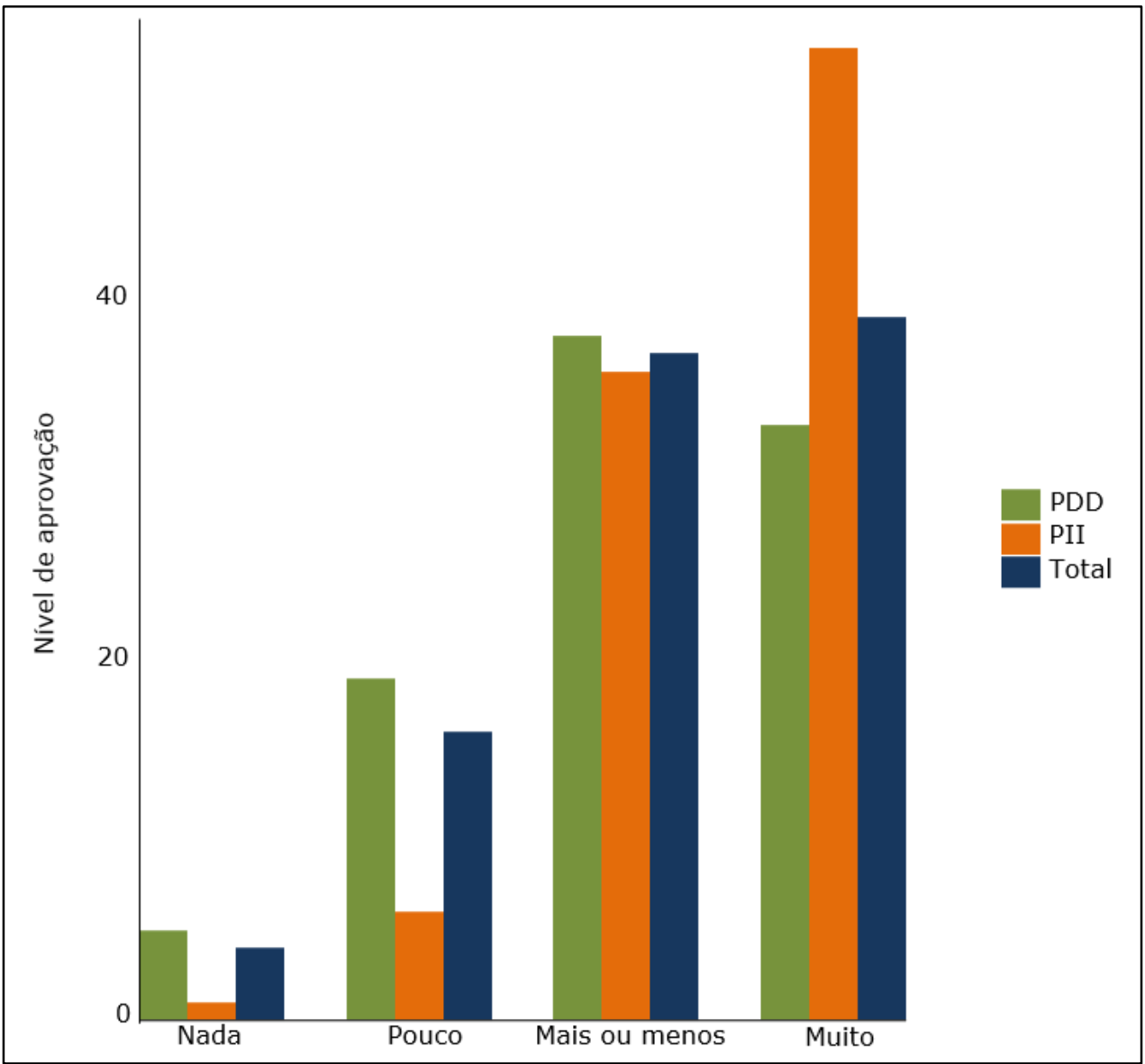

Fonte: Elaboração própria com base em dados do projeto "Brasil, as Américas e o mundo" (Almeida et al., 2014).

Nota: Pergunta - Quanto você acredita que a atração de investimentos beneficia Brasil? Muito/Mais ou menos/Pouco/Nada/NS/NR.

As evidências apresentadas indicam, portanto, um forte apoio à globalização econômica e ao livre comércio no Brasil. Elas confirmam achados das poucas pesquisas de opinião sobre o tema realizadas nos últimos 30 anos no país ${ }^{6}$. Percebe-se, também, significativa permanência das opiniões ao longo do tempo. A proporção de atitudes favoráveis à globalização e ao livre comércio, ainda que não seja a mesma, é elevada

6 Temos conhecimento de levantamentos com amostras nacionais realizados pelo Instituto Brasileiro de Opinião Pública e Estatística (Ibope, 1990), Datafolha (1995), Latinobarómetro (1996), além do survey realizado por Baker (2003, 2010) em quatro cidades brasileiras em 1995 e 2005 (Belém, Porto Alegre, Recife e São Paulo). Apesar de as perguntas terem formulação distinta em cada uma das pesquisas, os resultados variaram entre $60 \%$ e $75 \%$ de aprovação. 
(superior a 62\%) nos levantamentos realizados pelo projeto "O Brasil, as Américas e o Mundo", em 2010, 2014 e 2019 (Almeida, M. et al., 2010, 2014, 2019), período em que as orientações da política externa brasileira sofreram mudança radical, o que parece indicar que estamos em presença de atitudes, no sentido usualmente empregado pela literatura de cultura política, e não apenas de opiniões contingentes e voláteis?.

\section{Opinião pública, globalização e livre comércio}

As explicações clássicas sobre o apoio dos indivíduos à integração de economias nacionais ao sistema internacional - e, em especial, ao livre comércio entre nações - se baseiam em modelos econômicos que supõem que o interesse do indivíduo é a chave da formação de suas preferências. Grande parte dessa literatura apoia-se em formalizações da teoria das vantagens comparativas. Esse é o caso do modelo Heckscher-Ohlin ( $\mathrm{H}-\mathrm{O})$, que supõe que a atitude dos indivíduos com relação ao comércio internacional depende da dotação de fatores da economia doméstica e da atividade econômica que eles desempenham. De forma simplificada, esse modelo supõe que capital e trabalho - ou trabalhadores com habilidades específicas e trabalhadores sem habilidades específicas - se distribuem de forma diversa em diferentes países e nos diferentes setores produtivos dentro de cada país, proporcionando-Ihes vantagens comparativas específicas. Assim, aquelas economias nacionais - ou segmentos dela - dotadas de fatores abundantes e, por conseguinte, de vantagens comparativas, seriam mais beneficiadas pela abertura comercial para o exterior. Desse modo, indivíduos aí inseridos veriam com bons olhos o comércio internacional sem travas. Ao passo que onde não existem vantagens comparativas, mas sim desvantagens, a abertura comercial teria efeitos negativos e geraria opiniões igualmente negativas sobre ela.

Em outros termos, os efeitos distributivos sobre a renda - sejam eles referentes à dicotomia capital-trabalho ou à relação entre trabalhadores qualificados e os sem qualificação - seriam os determinantes centrais das atitudes individuais com relação ao comércio internacional.

Estudos empíricos feitos em países de economias avançadas, onde existe abundância de capital e de mão de obra qualificada, confirmaram o modelo H-O (Balistreri, 1997; Beaulieu, 2002; Fordham e Kleinberg, 2012; Jäkel e Smolka, 2013, 2017; Lake e Lindsey, 2013; Mayda e Rodrik, 2005; O’Rourke e Sinnott, 2006; Rho e Tomz, 2017; Scheve e Slaughter, 2001). Naquele contexto, Scheve e Slaughter (2001), em um dos primeiros estudos com observação de opiniões individuais, mostraram que, nos Estados Unidos, trabalhadores pouco qualificados davam forte apoio a políticas protecionistas.

\footnotetext{
${ }^{7}$ A porcentagem dos entrevistados que pensam que a globalização é boa para economia brasileira foi $73 \%$ em 2010, 62\% em 2014 e 76\% em 2019. Nos mesmos anos, a proporção dos que indicaram que o livre comércio é bom para a economia brasileira foi $69 \%, 63 \%$ e $72 \%$, respectivamente. Decidimos usar os dados de 2014 , porque eles são menores do que os dos outros anos (2010 e 2019) e, nessa medida, permitem-nos um teste mais exigente da relação da variável dependente com as variáveis independentes selecionadas.
} 
Outros estudos, na contramão dos modelos de dotação de fatores, sustentam que os indivíduos com nível educacional mais elevado estariam mais inclinados a apoiar medidas de abertura econômica. Esse grupo teria maior facilidade de se adaptar às mudanças no mercado de trabalho, independentemente da dotação de fatores em seu país (Ardanaz, Murillo e Pinto, 2013; Beaulieu, Yatawara e Wang, 2005; Blonigen, 2011; Kagitani e Harimaya, 2017; Kaltenthaler, Gelleny e Ceccoli, 2004). Dessa forma, a correlação encontrada entre pouca qualificação e protecionismo econômico não seria resultado da propensão dos trabalhadores pouco qualificados a rejeitarem o livre comércio, mas sim dos qualificados a se adaptarem às mudanças que a integração econômica impõe sobre o livre comércio. Na mesma direção, Kagitani e Harimaya (2017, p. 22), estudando o Japão, mostraram que os trabalhadores menos qualificados, independentemente da inserção setorial na economia, tendem a sentir-se mais inseguros com o crescimento do movimento de bens, capitais e pessoas entre fronteiras, produzido pela globalização.

Não obstante a maior prevalência de explicações econômicas baseadas no autointeresse, alguns trabalhos apresentam evidências do impacto das ideias e ideologias políticas nas avaliações da globalização e livre comércio (Guisinger, 2009; Hainmueller e Hiscox, 2006; Herrmann, Tetlock e Diascro, 2001; Rathbun, Kertzer e Paradis, 2017; Rho e Tomz, 2015). Alguns autores enfatizam o impacto do nacionalismo de tipo xenófobo, que se manifesta como aversão ao estrangeiro ou como simples preconceito com relação ao que vem de fora (Bekhuis, Lubbers e Verkuyten, 2014; Kaltenthaler e Miller, 2013; Kuo e Naoi, 2015; Mansfield e Mutz, 2009; Sabet, 2013), enquanto Kaltenthaler e Miller (2013) ressaltam a importância da percepção dos riscos e benefícios resultantes de trocas culturais. A aceitação das trocas culturais indicaria o grau de cosmopolitismo do indivíduo e seria peça central de um sistema de crenças no qual o comércio internacional é visto como oportunidade de experimentar novos produtos e interagir com o mundo mais amplo.

Por fim, destacam-se duas outras abordagens que se afastam da explicação assentada no autointeresse econômico. A primeira enfatiza a diferença entre gêneros (gender gap) na avaliação da globalização e do livre comércio internacional, mostrando que, em geral, as mulheres são mais protecionistas (Beaulieu e Napier, 2008; Burgoon e Hiscox, 2008; Drope e Chowdhury, 2014; Mansfield, Mutz e Silver, 2015; Kagitani e Harimaya, 2017; Bromhead, 2018). Burgoon e Hiscox (2008) e Hiscox (2006) atribuem preferências distintas entre gêneros em razão de o número de homens em cursos de economia ser maior do que o de mulheres. Mansfield, Mutz e Silver (2015) indicam que as mulheres seriam mais antiglobalistas por serem mais avessas à competição e por estarem mais preocupadas com mudanças em seus postos de trabalho. Já Naoi e Kume (2015) argumentam que a situação das mulheres no mercado de trabalho é mais instável e que elas são consumidoras mais preocupadas com a segurança e a qualidade dos alimentos e produtos.

A segunda abordagem considera que a avaliação feita pelos indivíduos sobre os parceiros comerciais influi nas suas atitudes em relação ao livre comércio. Simpatia pelo país parceiro seria mais importante do que o cálculo autointeressado dos benefícios ou 
desvantagens de acordos de livre comércio (Chiang, Liu e Wen, 2013; DiGiuseppe e Kleinberg, 2018; Hicks, Milner e Tingley, 2014; Naoi e Urata, 2013; Spilker, Bernauer e Umaña, 2016, 2018).

A maior parte dos estudos citados tem como referência empírica países desenvolvidos. Há poucos trabalhos sobre as atitudes dos latino-americanos, menos ainda sobre as dos brasileiros. Em geral, eles contradizem os modelos de dotação de fatores, abrindo espaço para outras explicações, baseadas no capital humano, na lógica do consumidor, na influência das elites políticas ou no papel das ideias.

Assim, Beaulieu, Yatawara e Wang (2005) analisaram a preferência de cidadãos em relação à integração regional em 17 países da América Latina com dados do Latinobarómetro de 1996 e mostraram que, em média, os trabalhadores com melhor qualificação, que são a minoria da força de trabalho, apoiam mais a integração econômica do que os não qualificados, indo na contramão do modelo de dotação de fatores. Ao observar o efeito em cada país, o resultado se mantém significativo para apenas oito deles, incluindo o Brasil.

Esses achados foram confirmados por estudos posteriores que trataram especificamente do processo de integração regional na América Latina (Deutschmann e Minkus, 2018; Fattore e Fitzpatrick, 2016) e do apoio à globalização (Merino e Vargas, 2013). Em análise do caso argentino e buscando avaliar os efeitos de enquadramento (framing), Ardanaz, Murillo e Pinto (2013) encontraram resultados semelhantes e mostraram que o nível de escolaridade é fator preditivo da opinião do indivíduo sobre abertura econômica.

Hicks, Milner e Tingley (2014) refutam a hipótese Heckscher-Ohlin em estudo de caso sobre o referendo do Tratado de Livre Comércio entre Estados Unidos, América Central e República Dominicana (Cafta-RD) na Costa Rica. Os autores demonstram a importância da liderança exercida pelos partidos, fato que sublinha a relevância das elites. Esse tema, muitas vezes deixado de lado em estudos sobre formação de preferências relativas ao comércio internacional, já foi ressaltado por Baker (2010) em seu estudo sobre a América Latina. Em termos econômicos, os autores confirmam predições do modelo Ricardo-Viner ${ }^{8}$, ao encontrar maior apoio a acordos de comércio entre aqueles vinculados a setores exportadores.

Merecem destaque os trabalhos de Baker $(2003,2005,2010)$ sobre os países latinoamericanos e sobre o Brasil, especificamente. Seus resultados indicam que a explicação das preferências individuais se encontra no tipo de bem consumido. O consumidor propenso a adquirir produtos importados - ou expostos à concorrência dos importados - teria atitudes mais positivas sobre a abertura econômica, pois se veria beneficiado pela variedade de produtos disponíveis no mercado, com qualidade similar ou superior à nacional a preços menores. Já os consumidores de produtos exportáveis tenderiam a preferir a proteção, pois

\footnotetext{
${ }^{8} \mathrm{O}$ modelo Ricardo-Viner, também denominado modelo de fatores específicos, pressupõe baixa mobilidade de fatores de produção, com exceção do trabalho, indicando que o livre comércio beneficiaria firmas ou setores que detêm maior vantagem comparativa. Logo, o que determinaria a formação de preferências do indivíduo sobre livre comércio não seria a remuneração de fatores, resultante de sua abundância ou escassez, mas o setor no qual o indivíduo está inserido.
} 
o comércio internacional tende a aumentar os preços domésticos dos exportáveis ${ }^{9}$. De acordo com Baker, isso ocorreria apesar dos custos já impostos pelo livre comércio e das vantagens já trazidas pela abertura econômica.

Este artigo quer contribuir para o entendimento dos determinantes da preferência individual pela inserção da economia nacional no mercado internacional, observando atitudes em relação a dois fenômenos próximos mas distintos, quais sejam: livre comércio e globalização econômica. Focalizamos as opiniões relativas a seus impactos seja sobre a situação dos indivíduos, seja sobre diferentes dimensões da realidade econômica mais ampla. Em consonância com a literatura, apontamos que as atitudes se explicam por motivações econômicas, mas estas, por sua vez, passam pelo filtro de ideias e valores políticos.

O Brasil é um bom caso para o teste das explicações econômicas por dois motivos. Em primeiro lugar, a dotação de fatores no Brasil é o oposto daquela encontrada nos países desenvolvidos. A economia brasileira é intensiva em trabalho não qualificado, ao passo que o mundo desenvolvido é intensivo em capital e trabalho qualificado. Por isso, no Brasil - em termos puramente relacionados à dotação de fatores -, os mais educados, que aqui são fator escasso, deveriam ser menos propensos a apoiar o livre comércio. Ou seja, o contrário do previsto pelas teorias sobre capital humano e comércio, que associam educação à maior capacidade de adaptação às mudanças causadas pela integração econômica e a atitudes mais cosmopolitas e politicamente tolerantes.

Em segundo lugar, o Brasil tem economia relativamente fechada, tornando os efeitos da abertura sobre o consumo mais imediatamente sentidos pelos cidadãos do que suas consequências potenciais para o sistema produtivo. Os indivíduos não sabem de antemão quais serão os setores da economia beneficiados ou prejudicados em decorrência daquele processo. Mas os "ágios" nos preços de produtos nacionais que poderiam ser substituídos por importados - além da maior variedade disponível - são imediatamente percebidos, ainda mais em tempos de acesso fácil a empresas de comércio eletrônico de outros países.

\section{Explicando as opiniões dos brasileiros: o modelo}

Utilizamos dados do survey realizado no âmbito do projeto "O Brasil, as Américas e o mundo" (Almeida et al., 2014) para discutir os determinantes das opiniões do público brasileiro em relação à globalização e ao livre comércio. Fomos buscar na literatura as variáveis explicativas mais relevantes. Como nos interessam as percepções do impacto da globalização e do livre comércio tanto sobre a situação individual do entrevistado quanto sobre fenômenos socioeconômicos mais gerais, construímos duas variáveis dependentes distintas.

\footnotetext{
9 Uma proxy para mensuração da diversificação da cesta de bens consumidos seria a própria renda do indivíduo. Ceteris paribus, indivíduos com maior renda tendem a adquirir mais produtos importados e, portanto, se beneficiar mais da integração econômica.
} 
Variáveis dependentes

Criamos quatro indicadores de apoio à globalização e ao livre comércio a partir das perguntas sobre Apoio Autointeressado à Globalização (AG-vida), Índice de Apoio Genérico à Globalização (AG-I), Apoio Autointeressado ao Livre Comércio (ALC-vida), Índice de Apoio Genérico ao Livre Comércio (ALC-I), cuja distribuição de respostas está nos Gráficos 1 e 2 .

A variável $A G-I$ é uma medida resumo resultante do somatório das opções de resposta às quais atribuímos os seguintes valores: muito ruim $(-2)$; ruim $(-1)$; nem bom e nem ruim (0); bom (1); muito bom (2); não sei (0); não respondeu (0). Como temos uma bateria de perguntas sobre oito temas (Economia Brasileira, Empresas Brasileiras, Consumidores, Geração de Empregos, Estabilidade no Trabalho, Padrão de Vida, Gerações Futuras e Meio Ambiente), AG-I varia teoricamente entre -16 (respondente que entende que a globalização é muito ruim para o Brasil em todos os oito aspectos) e +16 (respondente que entende que a globalização é muito boa para o Brasil em todos os aspectos).

Por sua vez, para cada uma das perguntas sobre livre comércio, atribuímos os seguintes valores: bom (1), ruim ( -1$)$, não sei (0), não respondeu (0), depende (0). Como temos outra bateria de perguntas sobre seis temas (Economia Brasileira, Empresas Brasileiras, Nível de Vida, Trabalho, Agricultura e Meio Ambiente), a variável ALC-I tem valores entre -6 e +6 , seguindo a mesma lógica da variável $A G-1$.

As duas variáveis captam atitudes frente aos impactos mais abrangentes da abertura econômica ao exterior em diversas áreas da vida social.

Seguindo a mesma lógica, construímos variáveis dependentes que traduzem as percepções autointeressadas dos entrevistados. Na primeira, ALC-vida, o respondente indica se o livre comércio é bom (1), indiferente (0) ou ruim (-1) para o nível de vida de pessoas como ele; na segunda, AG-vida, capta a percepção das consequências da globalização econômica para o seu próprio padrão de vida: muito ruim (-2), ruim (-1), indiferente (0), bom (1), muito bom (2).

As estatísticas descritivas das quatro variáveis dependentes estão na Tabela 1. No Apêndice $B$, apresentamos os testes de avaliação de confiabilidade e validade das escalas por meio do Alfa de Cronbach e do Modelo de Rasch. 
Tabela 1

Estatísticas descritivas das variáveis dependentes

\begin{tabular}{|l|c|c|c|c|}
\hline & $\begin{array}{c}\text { Índice de Apoio Geral à } \\
\text { Globalização } \\
\text { (AG-I) }\end{array}$ & $\begin{array}{c}\text { Apoio } \\
\text { Autointeressado à } \\
\text { Globalização } \\
\text { (AG-vida) }\end{array}$ & $\begin{array}{c}\text { Índice de Apoio Ge- } \\
\text { ral ao } \\
\text { Livre Comércio } \\
\text { (ALC-I) }\end{array}$ & $\begin{array}{c}\text { Apoio } \\
\text { Autointeressado ao } \\
\text { Livre Comércio } \\
\text { (ALC-vida) }\end{array}$ \\
\hline Média & 3,32 & 0,46 & 2 & 0,44 \\
\hline DP & 4,68 & 0,9 & 3,39 & 0,83 \\
\hline Mediana & 4 & 1 & 2 & 1 \\
\hline Mínimo & -13 & -2 & -6 & -1 \\
\hline Máximo & 13 & 2 & 6 & 1 \\
\hline N & 1881 & 1881 & 1881 & 1881 \\
\hline
\end{tabular}

Fonte: Elaboração própria com base em dados do projeto "Brasil, as Américas e o mundo" (Almeida et al., 2014).

Variáveis independentes e controles

Escolhemos variáveis que foram utilizadas em estudos anteriores sobre o tema: Idade, Escolaridade, Renda, Ocupação, Sexo, Ideologia, Partido, Voto na Eleição de 2014, Nacionalismo Cultural, Atitude em Relação ao Estrangeiro e Avaliação do Contexto Político. Incluímos também uma variável binária que indica se o indivíduo pertence ao grupo PII (Público Interessado e Informado) ou PDD (Público Desinteressado e Desinformado).

Escolaridade e Renda são as duas variáveis explicativas centrais mobilizadas pela literatura especializada para dar conta da formação de preferência por razões econômicas. A primeira é uma proxy comumente utilizada para determinar o nível de habilidade e qualificação dos indivíduos e a segunda, uma proxy para mensurar a capacidade de consumo. Nossa variável Escolaridade é categórica e o baseline são os menos educados, ou seja, os não alfabetizados, os que apenas sabem ler e os que frequentaram a primeira etapa do ensino fundamental (até o $5^{\circ}$ ano completo do ensino fundamental). O segundo grupo abarca os que frequentaram a segunda etapa do ensino fundamental, tendo-o completado ou não (do $6^{\circ}$ ao $9^{\circ}$ ano do ensino fundamental). O terceiro grupo é composto pelos que possuem ensino médio incompleto ou completo. O quarto grupo inclui os que possuem ensino superior incompleto. Por fim, o quinto grupo abarca os que completaram o ensino superior, com ou sem pós-graduação.

A variável Renda, também categórica, corresponde à renda individual mensal. Optamos pela utilização da renda individual, pois as explicações econômicas baseiam-se na posição do indivíduo como produtor/trabalhador e consumidor no mercado. Nesse caso, o baseline abrange os que não possuem renda e os que ganham até 1 salário mínimo (SM). 0 segundo grupo é formado pelos que ganham mais de 1 SM até 2 SMs; o terceiro, pelos que recebem entre mais de 2 e 5 SMs; e o quarto grupo, pelos que têm remuneração superior a 5 SMs.

Em seguida, vêm as variáveis que expressam a posição político-ideológica do indivíduo, como Ideologia, Partido, Voto e Avaliação do Contexto Político. A variável Ideologia é uma medida categórica da autolocalização do indivíduo em uma escala direita-esquerda. 
A escala vai de 0 a 10, sendo 0 esquerda e 10 direita. Dividimos os entrevistados em quatro grupos: esquerda ( 0 a 3); centro (4 a 6); direita ( 7 a 10); o último grupo é composto por aqueles que não quiseram ou não souberam responder. A transformação da medida em categorias - esquerda, centro, direita, não sabe e não respondeu - é uma estratégia para não perdemos as informações da quarta categoria (não quiseram ou não souberam responder).

A variável Partido se refere à identificação partidária, captada pela pergunta: Normalmente você se considera mais apoiador de qual partido? Nesse caso, o baseline é ausência de identificação partidária. As demais preferências são: PSDB (1), PT (2) e PMDB (3). A quarta categoria inclui todos os outros partidos (4) e na quinta e última estão os que não souberam ou não quiseram responder (5).

A variável Voto capta o voto declarado nas eleições de 2014. Criamos as seguintes categorias: voto no PT (baseline), voto no PSDB (1), não votou (2), não sabe ou não respondeu (3) e voto em outro partido (4). Procuramos controlar os efeitos do humor político do entrevistado por meio da variável Avaliação do Contexto Político $(A C P)$, uma dummy que indica se o respondente tem uma visão negativa do cenário político mundial, retrospectivo e prospectivo, no intervalo de 10 anos. Entrevistado identificado com (1) respondeu que o mundo piorou nos últimos 10 anos e vai piorar nos próximos 10 anos.

Por fim, recorremos a outras variáveis de controle tradicionais, que classificam os respondentes pela ocupação profissional, sexo e idade. A variável Ocupação está dividida em sete categorias, tendo os servidores públicos como baseline. As categorias seguintes são: participante do setor privado: funcionário e empresário (1), profissional liberal (2), desempregado (3) e pessoa fora da população economicamente ativa (PEA), incapacitado, do lar, estudante e aposentado (4).

A variável Sexo indica se o indivíduo é do sexo feminino (0) ou masculino (1). A variável Idade também é categórica: o baseline abrange os jovens de 16 a 29 anos, em seguida os jovens adultos de 30 a 39 anos, os adultos de 40 a 49 anos, os adultos de 50 a 59 anos e, finalmente, adultos com mais de 60 anos. Na Tabela 2, apresentamos as estatísticas descritivas das variáveis independentes. 
Tabela 2

Estatísticas descritivas das variáveis independentes

\begin{tabular}{|c|c|c|c|c|c|}
\hline Variáveis & Categorias & $\mathbf{n}$ & Variáveis & Categorias & $\mathbf{n}$ \\
\hline Idade & & & Escolaridade & & \\
\hline 16 a 29 anos & 0 & 636 & Até $5^{\circ}$ ano ensino fundamental & 0 & 361 \\
\hline 30 a 39 anos & 1 & 403 & Até ensino fundamental completo & 1 & 387 \\
\hline 40 a 49 anos & 2 & 337 & Até ensino médio completo & 2 & 836 \\
\hline 50 a 59 anos & 3 & 249 & Ensino superior incompleto & 3 & 133 \\
\hline mais de 60 anos & 4 & 256 & Ensino superior completo & 4 & 164 \\
\hline Total & & 1881 & Total & & 1881 \\
\hline IPI & & & Sexo & & \\
\hline PDD & 0 & 1417 & Feminino & 0 & 985 \\
\hline PII & 1 & 464 & Masculino & 1 & 896 \\
\hline Total & & 1881 & Total & & 1881 \\
\hline Ocupação & & & Renda & & \\
\hline Servidores públicos & 0 & 115 & Sem renda e até $1 \mathrm{SM}$ & 0 & 942 \\
\hline Setor privado & 1 & 545 & 1 a 2 SMs & 1 & 554 \\
\hline Profissional liberal & 2 & 566 & Mais de 2 a 5 SMs & 2 & 290 \\
\hline Desempregado & 3 & 151 & Mais de 5 SMs & 3 & 75 \\
\hline Fora da PEA & 4 & 504 & Total & & 1861 \\
\hline Total & & 1881 & & & \\
\hline Partido & & & Voto & & \\
\hline Sem partido & 0 & 405 & PT & 0 & 840 \\
\hline PSDB & 1 & 347 & PSDB & 1 & 495 \\
\hline PT & 2 & 713 & Não votou & 2 & 326 \\
\hline PMDB & 3 & 130 & Não sabe/Não respondeu & 3 & 113 \\
\hline Outros & 4 & 206 & Outros & 4 & 107 \\
\hline Não sei/Não respondeu & 5 & 80 & Total & & 1881 \\
\hline Total & & 1881 & & & \\
\hline $\begin{array}{l}\text { Contrário ou neutro a } \\
\text { ideias e costumes } \\
\text { estrangeiros }\end{array}$ & 0 & 767 & $\begin{array}{l}\text { Contrário ou neutro à presença de } \\
\text { estrangeiros }\end{array}$ & 0 & 572 \\
\hline $\begin{array}{l}\text { Favorável a ideias e cos- } \\
\text { tumes estrangeiros }\end{array}$ & 1 & 1114 & $\begin{array}{l}\text { Favorável à presença de } \\
\text { estrangeiros }\end{array}$ & 1 & 1309 \\
\hline Total & & 1881 & Total & & 1881 \\
\hline $\begin{array}{l}\text { Avaliação contexto } \\
\text { político (AVP) }\end{array}$ & & & Ideologia & & \\
\hline Visão não negativa & 0 & 1340 & Esquerda & 0 & 204 \\
\hline Visão negativa & 1 & 541 & Centro & 1 & 514 \\
\hline \multirow{3}{*}{ Total } & & 1881 & Direita & 2 & 856 \\
\hline & & & Sem partido & 3 & 507 \\
\hline & & & Total & & 1881 \\
\hline
\end{tabular}

Fonte: Elaboração própria com base em dados do projeto "Brasil, as Américas e o mundo" (Almeida et al., 2014).

Analisamos os efeitos de nossas variáveis independentes para as quatro variáveis dependentes. Estimamos quatro modelos distintos de regressão, logística ordinal para as variáveis de autointeresse e logísticas lineares para as variáveis índices, e analisamos detalhadamente cada um dos resultados ${ }^{10}$. Nas análises, agregamos o Público Interessado e

10 Nas Tabelas A1 e A2 do Apêndice A, apresentamos os resultados completos para os quatro modelos estimados. Os coeficientes de apoio autointeressado correspondem aos modelos das colunas (2) e (4) da Tabela A2 (modelos logísticos ordenados). Os coeficientes das variáveis índices correspondem aos modelos (4) e (10) 
Informado (PII) e o Público Desinteressado e Desinformado (PDD). Nesse caso, incluímos a variável dummy Interesse e Informação sobre política Internacional (IPI), como valor 1 para o PII. Nas Tabelas A1 e A2 do Apêndice A estimamos também os mesmos modelos para os grupos PII e PDD. A escolha de modelos lineares ou logísticos ordinais não afeta os resultados.

\section{Resultados}

Os principais resultados estão dispostos no Gráfico 5, que mostra os coeficientes dos efeitos de variáveis independentes selecionadas. Nossa expectativa é que os efeitos das variáveis econômicas Renda e Escolaridade sejam significativos para Apoio Autointeressado (variáveis $A L C$-vida e AG-vida), à esquerda no quadro, pois medem as atitudes dos brasileiros diante da integração econômica à economia internacional a partir da perspectiva do interesse próprio dos entrevistados. Por seu turno, as variáveis relacionadas a ideologia política, nacionalismo e atitudes em relação a estrangeiros e as que dizem respeito ao sexo dos entrevistados devem ter efeito mais acentuado sobre Índice de Apoio Genérico ( $A L C-I$ e $A G-I)$. Seus resultados aparecem à direita no quadro.

\section{Gráfico 5 \\ Determinantes da formação de preferência individual do brasileiro pelo livre comércio e pela globalização? (coeficientes selecionados)}

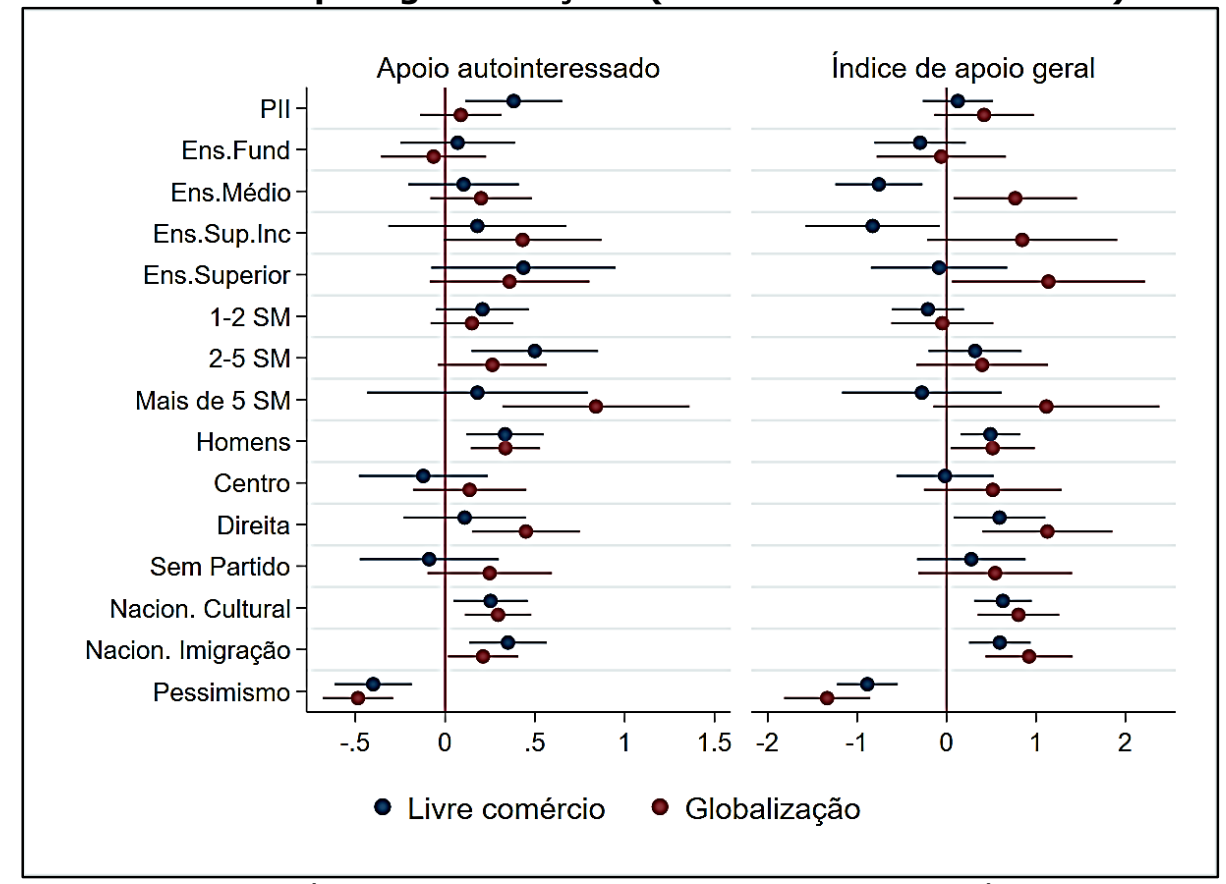

Fonte: Elaboração própria com base em dados do projeto "Brasil, as Américas e o mundo" (Almeida et al., 2014).

da Tabela A1 (modelos lineares). 
A existência de várias categorias das variáveis Escolaridade e Renda dificulta a análise dos coeficientes do Gráfico 5. Por isso, optamos por analisar mais detalhadamente os mesmos resultados nos Gráficos 6 e 7.

Os resultados do Gráfico 6 indicam um padrão interessante. De um lado, as variáveis que medem a percepção autointeressada da globalização e do livre comércio ( $A L C$-vida e AG-vida) não são afetadas pelos diferentes níveis de escolaridade. Todos os intervalos de confiança para as duas categorias (IC - 90\%) são sobrepostos, indicando que as estimações não são diferentes do ponto de vista estatístico. Por outro lado, quando analisamos as variáveis índices, que procuram captar as atitudes sobre as consequências genéricas da globalização e do livre comércio, encontramos efeitos opostos. No caso do livre comércio, a expectativa de apoio é menor - e estatisticamente significativa - quando os indivíduos têm ensino médio do que quando os indivíduos são analfabetos ou cursaram até o $5^{\circ}$ ano do ensino fundamental. Há uma diferença de 0,7 ponto na escala de apoio ao livre comércio. Já quando se trata da globalização, a situação se inverte. Ou seja, os mais educados são menos favoráveis ao livre comércio e mais propensos a apoiar a globalização.

Esse resultado parece indicar que a escolaridade não é um bom indicador das habilidades no mercado de trabalho, mas sim da propensão do indivíduo em aceitar maior abertura para o mundo em diversas dimensões da vida, além da economia. Nesse sentido, nossa variável globalização parece mais adequada como indicador de um fenômeno multidimensional, que ultrapassa o intercâmbio econômico, enquanto a variável livre comércio remete diretamente à dimensão da troca de bens no mercado internacional.

É importante enfatizar que as noções de livre comércio e globalização, embora associadas, não descrevem o mesmo fenômeno. O coeficiente de correlação de Pierson entre as duas variáveis índices é de apenas 0,29 , a indicar que estão positivamente associadas, mas mensuram fenômenos distintos. A correlação entre as variáveis de avaliação autointeressada dos dois fenômenos também apresenta resultados semelhantes. 0 coeficiente Rho de Spearman é de 0,25.

Em suma, a educação não parece afetar a percepção dos efeitos da globalização e do livre comércio da ótica do autointeresse. Mas afeta de maneira oposta as variáveis que capturam as opiniões sobre os efeitos mais gerais dos dois fenômenos. Os menos educados tendem relativamente a ver mais positivamente o livre comércio do que a globalização quando comparados com os grupos com maior educação. Os efeitos sobre as percepções a respeito do livre comércio, contudo, são menos claros. A tendência de apoio ao protecionismo aumenta com a escolaridade, apesar de o grupo mais educado - ensino superior completo ter expectativa de apoio similar à dos menos educados. Assim, nossos resultados contrastam com as teorias ao afirmar que os indivíduos com habilidades médias tendem a ser mais protecionistas.

Também no que respeita à globalização, as previsões do modelo de Hecksher-Ohlin não se confirmam. Segundo ele, os mais educados no Brasil deveriam ser menos propensos a defender a integração à economia internacional uma vez que o capital humano qualificado 
é recurso pouco abundante no país. Isso não se verificou em nenhum de nossos modelos. Quer se trate de livre comércio ou da globalização, as atitudes positivas aumentam no topo da escolaridade.

Em suma, as teorias econômicas não dão conta de explicar os efeitos da educação sobre as atitudes dos brasileiros diante da globalização e do livre comércio. Outros efeitos da educação, que não a qualificação profissional, acabam se sobrepondo, especialmente no caso de atitudes dos indivíduos com educação superior ${ }^{11}$.

\section{Gráfico 6 \\ Predições do efeito de Escolaridade sobre Integração à Economia Internacional}

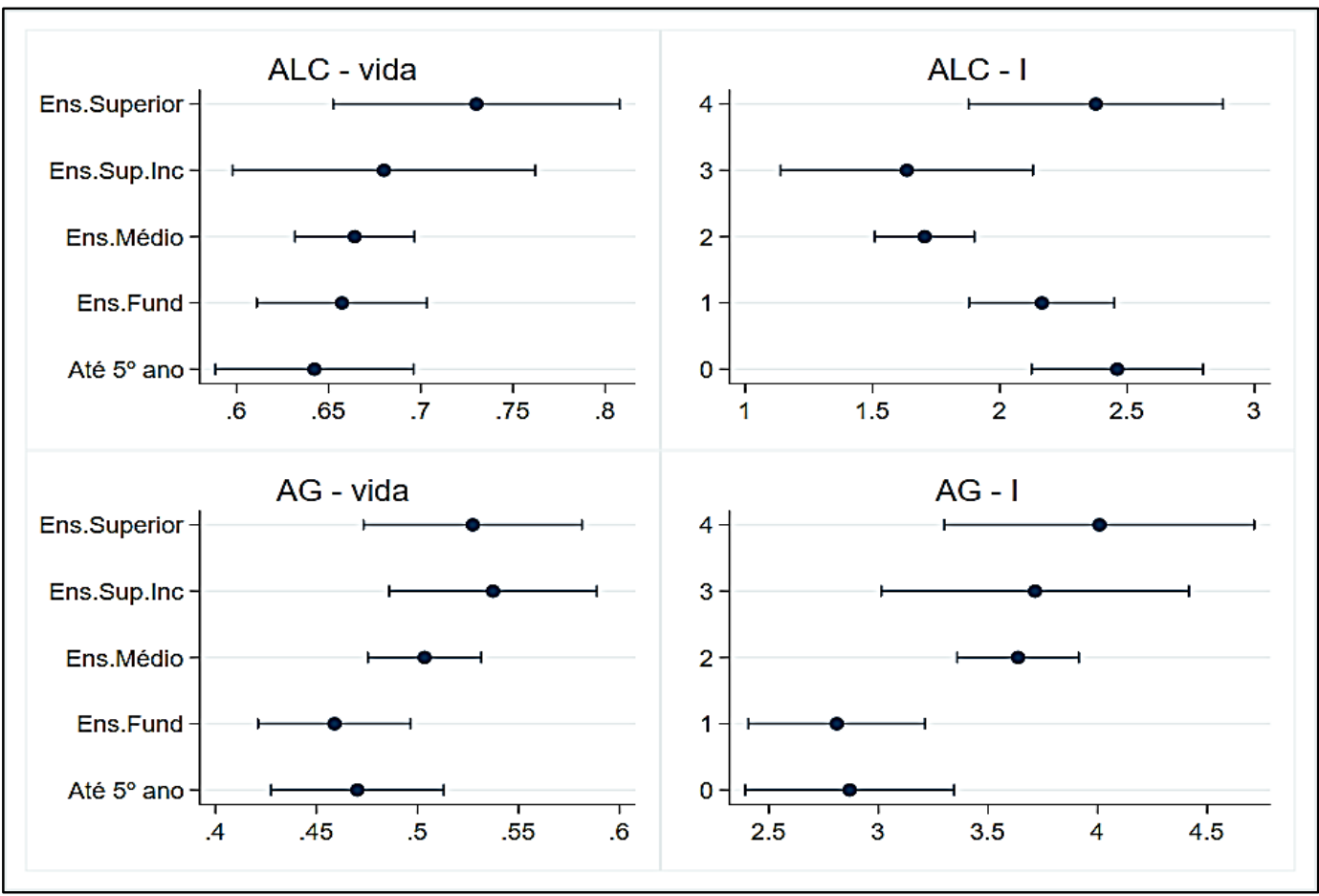

Fonte: Elaboração própria com base em dados do projeto "Brasil, as Américas e o mundo" (Almeida et al., 2014).

Predições dos modelos estimados para o Gráfico 5 e para as Tabelas A1 e A2 no Apêndice. Outras variáveis foram fixadas na média. ICs de $90 \%$. No eixo horizontal, são apresentadas as probabilidades de respostas positivas nos modelos logísticos ordenados ALC-vida: 1 (bom) e Glob-vida: 1 (bom) e o valor previsto nos modelos lineares ( $A L C-I$ e $A G-I)$. As predições tomam como base a média das outras covariáveis.

A literatura especializada estabeleceu relação positiva entre renda e disposição para apoiar o livre comércio internacional. A variável é utilizada como proxy de propensão ao

\footnotetext{
11 Para explorar as diferenças encontradas no Gráfico 6, testamos as mesmas relações apenas para a avaliação dos efeitos da globalização e do livre comércio sobre o meio ambiente, questão na qual é maior o pessimismo dos entrevistados. O resultado se repete, de forma ainda mais nítida, quando se trata do impacto do livre comércio e perde significância no caso da globalização. Os resultados do modelo aplicado apenas ao meio ambiente são apresentados no Apêndice A (Gráfico A6).
} 
consumo de importados: quanto maior a renda, maior e mais diversificada é a cesta de bens, inclusive de bens importados. Encontramos confirmação desse achado: indivíduos com maior renda tendem a dar mais apoio ao livre comércio e à globalização, como se pode observar nos Gráficos 5 e 7.

No Gráfico 7, apresentamos os valores preditos pelos modelos para todas as categorias de renda. O efeito é mais importante quando se trata do que chamamos de apoio autointeressado (ALC-vida e AG-vida).

A probabilidade de que um indivíduo apoie o livre comércio aumenta com a renda. A probabilidade de o indivíduo de menor renda (até $1 \mathrm{SM}$ ) ver positivamente o livre comércio é de $64 \%$, enquanto é de $68 \%$ entre os que ganham mais de 1 a 2 SMs. Essa probabilidade alcança 74\% para os indivíduos com renda de mais de 2 a 5 SMs - um aumento de 10 pontos percentuais em relação aos mais pobres quando se trata de apoio autointeressado. Os resultados são mais incertos para a categoria mais rica, que inclui menor número de indivíduos - apenas 75 -, pois a estimação de um intervalo de confiança grande não nos permite fazer comparações válidas. Por sua vez, não encontramos efeito significativo algum da renda sobre a visão genérica dos efeitos do livre comércio. Todos os intervalos de confiança das quatro categorias se sobrepõem, indicando não haver qualquer diferença válida entre elas.

No caso das opiniões sobre globalização ( $A G$-vida e $A G-I$ ), os pontos estimados para as categorias de maior renda são quase sempre maiores que os estimados para as categorias de menor renda. Outra vez, os efeitos são significativos apenas quando a variável dependente mensura a opinião relativa aos efeitos do livre comércio sob a lente do autointeresse. É de $47 \%$ a probabilidade de os mais pobres apoiarem a globalização. Ela aumenta para $50 \%$ entre os indivíduos com renda de 1 a 2 SMs, atinge $52 \%$ entre os entrevistados com renda intermediária e $58 \%$ entre os mais ricos - um incremento de cerca de 11 pontos percentuais. Por sua vez, todos os intervalos de confiança dos grupos de renda estão sobrepostos quando a variável dependente é o índice das atitudes em relação à globalização (AG-I). Um resultado sem significância estatística.

Os efeitos da renda sobre o apoio ao livre comércio e à globalização são mais claros nos modelos que medem o efeito das atitudes autointeressadas. Eles confirmam as explicações baseadas na lógica do consumo, ou seja, quanto maior a cesta de bens consumida por um indivíduo - incluindo importados -, maior será sua disposição a apoiar o livre comércio e a globalização econômica.

Já os efeitos da renda sobre as variáveis índices ( $A L C-1$ e $A G-1$ ), embora tenham a direção esperada, não são significativos, indicando a importância de introduzir outras variáveis explicativas, que não as econômicas.

Por essa razão, introduzimos variáveis relativas ao sexo dos respondentes e às orientações ideológicas e políticas. As variáveis Sexo, Nacionalismo Cultural e Atitude Contra Imigrantes são binárias.

Nosso modelo confirma estudos anteriores que afirmaram que mulheres são mais 
protecionistas que os homens e que essa diferença ocorre nos grupos mais informados e interessados (Tabela A1 no Apêndice $A)^{12}$. Ou seja, maior interesse e mais informação são elementos associados ao protecionismo feminino. Nosso estudo não elucida o mecanismo causal, mas traz mais informação para o debate ao mostrar que a diferença de gênero ocorre apenas entre os indivíduos mais interessados em temas internacionais.

Com relação à dimensão ideológica, os resultados são intuitivos e confirmam estudos anteriores.

\section{Gráfico 7}

Renda e Opinião Acerca da Integração à Economia Internacional

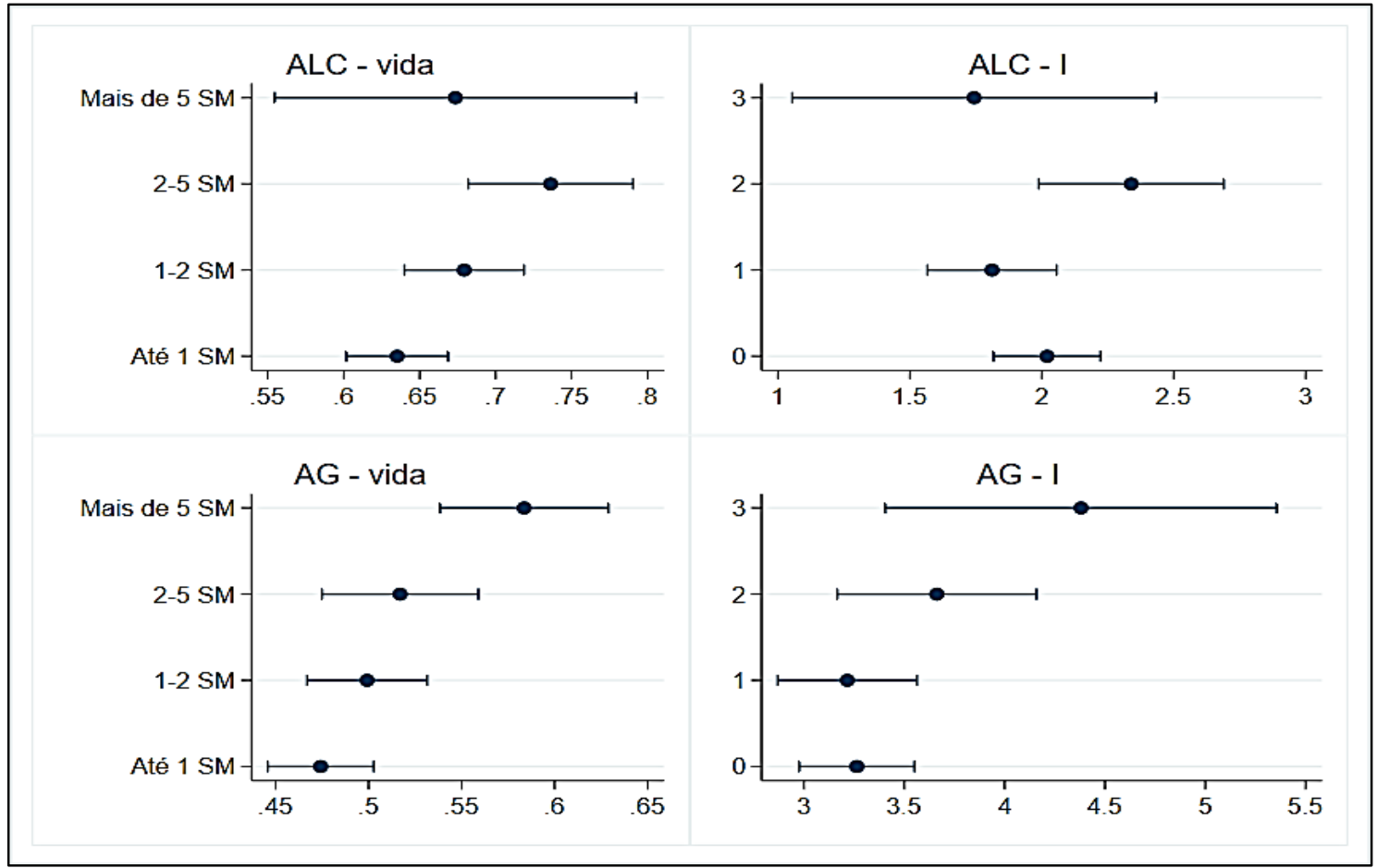

Fonte: Elaboração própria com base em dados do projeto "Brasil, as Américas e o mundo" (Almeida et al., 2014). Predições dos modelos estimados para o Gráfico 5 e para as Tabelas A1 e A2 no Apêndice. Outras variáveis foram fixadas na média. ICs de $90 \%$. No eixo horizontal são apresentadas as probabilidades de respostas positivas nos modelos logísticos ordenados ALC-vida: 1(bom) e Glob-vida: 1 (bom) e o valor previsto nos modelos lineares ( $A L C-I$ e $A G-I)$. As predições tomam como base a média das outras covariáveis.

O indivíduo que tem uma visão favorável à entrada de ideias e costumes estrangeiros no Brasil (Nacionalismo Cultural) e também à participação do estrangeiro no dia a dia da sociedade brasileira (Atitude contra Imigrantes) mostra maior apoio à globalização econômica e ao livre comércio. Outra vez, os efeitos são mais fortes para ALC-I e AG-I.

São contraditórios os efeitos das variáveis de cunho político - Partido, Voto, Ideologia

\footnotetext{
12 Na Tabela A1 do Apêndice A, dividimos a amostra em dois grupos, os PIIs e os PDDs, e reestimamos modelos lineares para cada um desses grupos nas colunas 2, 5, 8 e 11 (PDD); e 3, 6, 9 e 12 (PII).
} 
e ACP. Partido, assim como Voto, não tem impacto sobre a preferência do brasileiro em relação ao livre comércio e à globalização ${ }^{13}$. Mas ter votado em outro partido que não o PT e o PSDB reduz apoio ao livre comércio.

No entanto, encontramos efeitos significativos de Ideologia tanto sobre as duas variáveis índices ( $A L C-1$ e $A G-1$ ) quanto sobre $A G$-vida. Situar-se à direita no espectro político aumenta a propensão para apoiar o livre comércio e a globalização. Não há diferenças estatisticamente significativas entre as atitudes daqueles que se colocam à esquerda e ao centro ou as dos que não possuem partido político para as quatro variáveis dependentes.

O humor político (ACP) também tem impacto estatisticamente significativo sobre preferências relativas a livre comércio e globalização, para todas as variáveis dependentes. Os pessimistas, que têm visão retrospectiva e prospectiva negativa do cenário político mundial, são menos propensos a apoiar a abertura econômica para o exterior.

Nossa análise também indica baixa influência dos fatores Ocupação e Idade do respondente ${ }^{14}$. Não há diferenças entre as quatro categorias ocupacionais comparadas com a posição dos servidores públicos sobre a opinião relativa à globalização, qualquer que seja a forma de medi-la. Diferenças significativas aparecem apenas na opinião sobre livre comércio. Todas as categorias profissionais são mais liberalizantes do que a dos servidores públicos. Quando a variável dependente capta a opinião a respeito do impacto do livre comércio sobre a vida do indivíduo ( $A L C$-vida), os que não participam do mercado de trabalho (Não- PEA) têm atitudes mais positivas ${ }^{15}$. A Idade não tem qualquer efeito sobre as preferências.

Finalmente, constatamos que ter informação e interesse por questões internacionais tem efeito positivo sobre apoio à abertura econômica para o exterior em todos os modelos (variável IPI, Gráfico 5), embora seja estatisticamente significativo apenas no caso do apoio autointeressado ao livre comércio.

Na Tabela $A 1$ do Apêndice $A$, estão os resultados completos das estimações dos modelos lineares, em que dividimos as amostras em PII e PDD. Além disso, nos Gráficos A1, A2, A3, A4 e A5, (Apêndice A), apresentamos os efeitos preditivos de cada variável independente, respectivamente, voto em 2014, identificação partidária, idade, ideologia e ocupação.

\section{Conclusão}

Nossos dados indicam a existência de significativo apoio no público brasileiro à integração da economia nacional aos mercados globais. Essa afirmação vale para a abertura

\footnotetext{
13 Os resultados para Partido e Voto não estão no Gráfico 5, mas na Tabela A1 e nos Gráficos A1 e A2 no Apêndice A.

14 Os resultados para Ocupação e Idade não estão no Gráfico 5, mas na Tabela A1 e A2, no Apêndice A.

$15 \mathrm{Em}$ todas as análises, unificamos as categorias funcionário do setor privado e empresário, pois os resultados são semelhantes nos modelos em que estimamos as duas categorias em separado. Dessa forma, para simplificar a exposição dos dados, unificamo-las numa mesma categoria.
} 
ao exterior vista do prisma tanto do livre comércio quanto da globalização. Eles corroboram levantamentos anteriores feitos pelo Ibope (1990), Datafolha (1995), Latinobarómetro (1996), Baker (2003, 2010) e projeto "O Brasil, as Américas e o mundo" (2010).

A constatação pura e simples de que os brasileiros são favoráveis à maior integração da economia nacional ao mercado global não representa novidade. No entanto, é bastante notável que essa atitude tenha se mantido ao longo de quase três décadas, durante as quais houve variação no contexto econômico e no debate sobre os estilos de desenvolvimento desejáveis e possíveis.

Ademais, nossos resultados contribuem para os estudos sobre a formação de preferência individual em temas de economia política, ao mostrar que não encontramos evidências que corroborem as previsões de modelos consagrados, como o de HeckscherOhlin ( $\mathrm{H}-\mathrm{O})$. O caso brasileiro é interessante por permitir uma separação clara dos efeitos previstos da educação em termos da tolerância ao estrangeiro e dos efeitos no mercado de trabalho, o que não ocorre nos países desenvolvidos, onde ambas as explicações apontam que os mais educados seriam mais propensos a atitudes favoráveis à integração econômica. No caso analisado, a escolaridade não possui efeitos relevantes e consistentes sobre a propensão do indivíduo a uma visão positiva da integração à economia internacional. Os grupos detentores de maior capital humano - o fator escasso no modelo $\mathrm{H}-\mathrm{O}$ para o caso do Brasil - não são consistentemente mais protecionistas que os menos qualificados - fator abundante na economia brasileira.

Encontramos evidências mais consistentes no que diz respeito às explicações que analisam os efeitos da propensão ao consumo de importados sobre as atitudes próliberalização econômica. De fato, a renda individual - proxy da propensão do indivíduo a consumir - está associada a atitudes positivas em relação à economia internacional. Nossos achados indicam que pessoas do estrato $C$ de renda são mais propensas a atitudes positivas em face do livre comércio e que os indivíduos dos estratos $A$, B e $C$ possuem maior propensão a encarar positivamente a globalização. Esses resultados são compatíveis com as explicações baseadas na lógica do consumidor, uma vez que essa hipótese indica que os indivíduos mais propensos a comprar produtos importados seriam mais favoráveis ao livre comércio e à globalização.

Acreditamos que o fato de o Brasil ser pouco integrado à economia internacional em comparação com países de mesmo perfil é fator que pode gerar uma situação ambígua no processo de formulação das preferências do brasileiro. Isso porque o contexto brasileiro torna o respondente menos sensível às potenciais transformações que a integração da economia nacional aos mercados globais pode provocar no mercado de trabalho. E, ao mesmo tempo, o deixa mais exposto aos efeitos que a proteção econômica provoca no aumento do custo de produtos importados, principalmente com a maior exposição às informações dos mercados internacionais pelo fácil acesso às empresas de comércio eletrônico de outros países. Atualmente, não seria exagero classificar a economia brasileira 
como relativamente fechada, se comparada à dos países emergentes ou membros da $\mathrm{OCDE}^{16}$.

Por conseguinte, o brasileiro, na condição de consumidor, tenderia a ver positivamente a integração econômica, por perceber o ônus do protecionismo em termos de preços mais altos, qualidade inferior e pouca diversificação de bens acessíveis. Ao mesmo tempo, não estaria exposto de maneira significativamente clara aos possíveis efeitos negativos e positivos da abertura da economia para o mercado de trabalho, o emprego e a distribuição dos ganhos.

Tratamos de separar os efeitos de variáveis que medem o autointeresse de maneira mais direta dos efeitos de variáveis que captam percepções dos efeitos mais abrangentes da globalização e do livre comércio. Os resultados confirmam que existem diferenças de atitude quando a pergunta trata das duas situações. Tanto num caso quanto no outro, as variáveis que medem valores e ideologia têm efeitos significativos, embora sejam mais fortes quando se trata das consequências mais gerais da globalização e do livre comércio.

Nossas evidências também indicam que a posição ideológica à direita está associada à maior aceitação da integração econômica, assim como o nacionalismo aumenta a probabilidade de uma visão mais negativa. Por último, mas não menos importante, os resultados confirmam que as mulheres são mais protecionistas que os homens. No entanto, há indicações de que esses efeitos estão concentrados na população com maior interesse e informação sobre as relações internacionais. Não há diferenças entre homens e mulheres não informados ou não interessados em questões internacionais. Tal resultado joga luz sobre o debate dos mecanismos que explicam a existência de diferença de opinião segundo o sexo, tema que requer aprofundamento tanto teórico quanto empírico.

São muitos os desafios na agenda de pesquisa sobre a formação de preferências individuais em relação à globalização econômica. Ainda não estão claros os mecanismos causais específicos que explicariam as correlações encontradas neste artigo, assim como os meios pelos quais os indivíduos adquirem e processam informação sobre temas de comércio internacional. Além disso, não sabemos quanto a capacidade de compreensão individual dos efeitos pouco intuitivos do livre comércio sobre a vida das pessoas pode afetar os resultados. Estudos futuros devem aprofundar a análise das interações entre as explicações econômicas e ideacionais, destrinchar os mecanismos causais principais, assim como descobrir quanto o nível de informação fática sobre os efeitos do comércio pode afetar as correlações mais fundamentais.

\footnotetext{
16 De acordo com Kume (2017), o Brasil possui a 14a maior tarifa média (13,5\%) entre os 134 países membros da Organização Mundial do Comércio $(\mathrm{OMC})$ e a $8^{\mathrm{a}}$ maior em relação a produtos industrializados (14,1\%) - a média mundial de tarifa aplicada é 3\%, ao passo que no Brasil é $10 \%$. Entre os $10 \%$ mais protegidos nesse setor, estão: Argentina, Brasil, Djibuti, Camarões, República Africana Central, Chade, Gabão, Zimbábue, Gâmbia, Bangladesh, Venezuela, Zâmbia, Tunísia e Paquistão.
} 


\section{Referências bibliográficas}

AlmeidA, M., et al. O Brasil, as Américas e o mundo segundo a opinião do público e dos líderes. São Paulo: Cebrap, 2010.

Cebrap, 2014

O Brasil, as Américas e o mundo segundo a opinião do público e dos líderes. São Paulo:

O Brasil, as Américas e o mundo segundo a opinião do público. São Paulo: Cebrap, 2019.

Ardanaz, M.; Murillo, M. V.; Pinto, P. M. "Sensitivity to issue framing on trade policy preferences: evidence from a survey experiment". International Organization, vol. 67, no 2, p. 411-437, abr. 2013. BAKER, A. "Why is trade reform so popular in Latin America? A consumption-based theory of trade policy preferences". World Politics, vol. 55, no 3, p. 423-55, 2003.

. "Who wants to globalize? Consumer tastes and labor markets in a theory of trade policy beliefs". American Journal of Political Science, vol. 49, no 4, p. 924-938, 2005.

The market and the masses in Latin America: policy reform and consumption in liberalizing economies. Cambridge; New York, NY: Cambridge University Press, 2010.

BALISTRERI, E. J. "The performance of the Heckscher-Ohlin-Vanek Model in predicting endogenous policy forces at the individual level". The Canadian Journal of Economics/Revue Canadienne d'Economique, vol. 30, no 1, p. 1-17, 1997.

BeAulieu, E. "Factor or industry cleavages in trade policy? An empirical analysis of the StolperSamuelson Theorem". Economics \& Politics, vol. 14, no 2, p. 99-131, 2002.

Beaulieu, E.; NAPier, M. "Why are women more protectionist than men?". Manuscrito não publicado. Department of Economics, University of Calgary, 2008. Disponível em:

<http://www.uvic.ca/socialsciences/economics/assets/docs/pastdept-3/beaulieu.pdf>. Acesso em: 8 nov. 2008.

Beaulieu, E.; Yatawara, R. A.; Wang, W. G. "Who supports free trade in Latin America?". The World Economy, vol. 28, no 7, p. 941-958, 2005.

BeKHUIS, H.; LUBbers, M.; VeRKUYTEN, M. "How education moderates the relation between globalization and nationalist attitudes". International Journal of Public Opinion Research, vol. 26, no 4, p. 487-500, 2014.

BLonigen, B. A. "Revisiting the evidence on trade policy preferences". Journal of International Economics, vol. 85, no 1, p. 129-135, 2011.

Boone, W. J.; StAVer, J. R.; YALE, M. S. Rasch analysis in the human sciences. [s.I.] Springer Netherlands, 2014.

BRomheAD, A. D. "Women voters and trade protectionism in the interwar years". Oxford Economic Papers, vol. 70, no 1, p. 22-46, 2018.

BuRgoon, B.; Hiscox, M. J. "The mysterious case of female protectionism: gender bias in the attitudes and politics of international trade". In: American Political Science Association, Chicago, IL. Set. 2-5. 2004.

. "The gender divides over international trade: why do men and women have different views about openness to the world economy?", 2008. Manuscrito não publicado. Department of Government, Harvard University. Disponível em:

<https://www.researchgate.net/profile/Brian_Burgoon/publication/228432050_The_Gender_Divide_ov 
er_International_Trade_Why_Do_Men_and_Women_Have_Different_Views_about_Openness_to_the_ World_Economy/links/0deec51dfedd2170f5000000.pdf>. Acesso em: 1 jan. 2008.

CHACHAMOVICH, E. "Teoria de resposta ao item: aplicação do modelo Rasch em desenvolvimento e validação de instrumentos em saúde mental". Tese de doutorado. Faculdade de Medicina, Universidade Federal do Rio Grande do Sul, Porto Alegre, 2007.

CHIANG, C.-F.; LIU, J.-T.; WEN, T.-W. "Individual preferences for trade partners in Taiwan". Economics \& Politics, vol. 25, no 1, p. 91-109, 2013.

ClARO, H. G. "Validação dos instrumentos avaliação global das necessidades individuais - inicial e de rastreio rápido". Tese de Doutorado em Cuidados em Saúde. Universidade de São Paulo, São Paulo, 2015.

DATAFolha, Avaliação Fernando Henrique Cardoso (6 meses), junho de 1995, Brasil. In: Cesop - Centro de Estudos de Opinião Pública, Banco de Dados, Pesquisa no 432. Disponível em:

<https://www.cesop.unicamp.br/por/banco_de_dados/v/1486>. Acesso em: 1 jan. 2020.

Deutschmann, E.; Minkus, L. "Swinging leftward: public opinion on economic and political integration in Latin America, 1997-2010". Latin American Research Review, vol. 53, p. 38-56, 2018.

DiGiuseppe, M.; KLeinberg, K. B. "Economics, security, and individual-level preferences for trade agreements". International Interactions, vol. 45, no 2, p. 289-315, 2018.

DROPE, J.; ChOWdhury, A. "The puzzle of heterogeneity in support for free trade". Business and Politics, vol. 16 , no 3 , p. 453-479, out. 2014.

FATTORE, C.; FitzPATRICK, B. "Perceived inequality and support for trade liberalization in Latin America". Journal of International Trade Law and Policy, vol. 15, no 2-3, p. 102-114, 2016.

FordhaM, B. O.; KleinberG, K. B. "How can economic interests influence support for free trade?". International Organization, vol. 66, no 2, p. 311-328, abr. 2012.

GUISINGer, A. "Determining trade policy: do voters hold politicians accountable?". International Organization, vol. 63, no 3, p. 533-557, 2009.

Hainmueller, J.; Hiscox, M. J. "Learning to love globalization: education and individual attitudes toward international trade". International Organization, vol. 60, no 2, p. 469-498, abr. 2006.

Herrmann, R. K.; Tetlock, P. E.; Diascro, M. N. "How Americans think about trade: reconciling conflicts among money, power, and principles". International Studies Quarterly, vol. 45, no 2, p. 191218, 2001.

Hicks, R.; Milner, H. V.; Tingley, D. "Trade policy, economic interests, and party politics in a developing country: the political economy of Cafta-DR". International Studies Quarterly, vol. 58, no 1 , p. $106-117,2014$.

Hiscox, M. J. "Through a glass and darkly: attitudes toward international trade and the curious effects of issue framing". International Organization, vol. 60, n 3, p. 755-780, 2006.

Humphreys, L. G.; MONTANelli JR., R. G. "An investigation of the parallel analysis criterion for determining the number of common factors". Multivariate Behavioral Research, vol. 10, n 2, p. 193$205,1975$.

IBOPE - Instituto Brasileiro de Opinião e Estatística, Pesquisa de opinião pública sobre assuntos políticos e administrativos, Brasil, agosto de 1990. In: CESOP - Centro de Estudos de Opinião Pública, Banco de Dados, Pesquisa no 229. Disponível em:

<https://www.cesop.unicamp.br/por/banco_de_dados/v/474>. Acesso em: 1 jan. 2020. 
JÄKEL, I. C.; SMOLKA, M. "Individual attitudes towards trade: Stolper-Samuelson revisited". Open Economies Review, vol. 24, no 4, p. 731-761, 2013.

106, p. 1-19, 2017.

. "Trade policy preferences and factor abundance". Journal of International Economics, vol.

KAGITANI, K.; HARIMAYA, K. "Who fears or favors globalization? Evidence from individual-level survey data in Japan". International Economics, vol. 156, p. 61-76, 2017.

Kaltenthaler, K. C.; Gelleny, R. D.; Ceccoli, S. J. "Explaining citizen support for trade liberalization". International Studies Quarterly, vol. 48, no 4, p. 829-852, 2004.

Kaltenthaler, K.; Miller, W. J. "Social psychology and public support for trade liberalization". International Studies Quarterly, vol. 57, no 4, p. 784-790, 2013.

KUME, H. "Avaliação e reformulação da estrutura tarifária no Brasil" (online). Iepe/CdG, 2017. Disponível em: <http://iepecdg.com.br/artigos/avaliacao-e-reformulacao-da-estrutura-tarifaria-nobrasil/>. Acesso em: 1 jan. 2019.

KUO, J.; NAOI, M. Individual attitudes. In: MARTIN, L. (ed.). The Oxford handbook of the political economy of international trade, p. 99-118. Oxford University Press, USA, maio 2015.

LAKE, D. A.; LINDSEY, D. Moral foundations and individual-level foreign policy preferences. Rochester, NY: Social Science Research Network, 2013.

LATINOBARÓMETRO, 1996. Disponível em: <https://www.latinobarometro.org/latContents.jsp>. Acesso em: 1 jan. 2020.

MANSFIELD, E. D.; Mutz, D. C. "Support for free trade: self-interest, sociotropic politics, and out-group anxiety". International Organization, vol. 63, no 3, p. 425-457, jul. 2009.

Mansfield, E. D.; MutZ, D. C.; Silver, L. R. "Men, women, trade, and free markets". International Studies Quarterly, vol. 59, no 2, p. 303-315, 2015.

MAYDA, A. M.; RodRIK, D. "Why are some people (and countries) more protectionist than others?". European Economic Review, vol. 49, no 6, p. 1.393-1.430, 2005.

MERINO, M.; VARGAS, D. "How consumers perceive globalization: a multilevel approach". Journal of Business Research, vol. 66, no 3, p. 431-438, 2013.

NAOI, M.; KUME, I. "Workers or consumers? A survey experiment on the duality of citizens' interests in the politics of trade". Comparative Political Studies, vol. 48, no 10, p. 1.293-1.317, 2015.

NAOI, M.; URATA, S. "Free trade agreements and domestic politics: the case of the trans-pacific partnership agreement". Asian Economic Policy Review, vol. 8, n² 2, p. 326-349, 2013.

ONG, A. D.; DULmen, M. H. M. V. Oxford handbook of methods in positive psychology. [s.I.] Oxford University Press, 2006.

O'ROURKE, K. H.; SinNOTT, R. "The determinants of individual attitudes towards immigration". European Journal of Political Economy, vol. 22, no 4, p. 838-861, 2006.

PereirA, J. C. R. Bioestatística em outras palavras. São Paulo: Edusp, 2010.

Polit, D. F.; BECK, C. T. Fundamentos de pesquisa em enfermagem: avaliação de evidências para a prática da enfermagem. Porto Alegre: Artmed Editora, 2018. 
Rathbun, B. C.; Kertzer, J. D.; Paradis, M. "Homo diplomaticus: mixed-method evidence of variation in strategic rationality". International Organization, vol. 71, nº S1, p. S33-S60, abr. 2017.

RHO, S.; TOMz, M. "Industry, self-interest, and individual preferences over trade policy". Working paper $R \& R, 2015$

"Why don't trade preferences reflect economic self-interest?". International

Organization, vol. 71, nº S1, p. S85-S108, abr. 2017.

SABET, S. What's in a name? Isolating the effect of prejudice on individual trade references. Rochester, NY: Social Science Research Network, 2013.

SCheVE, K. F.; SLAUghteR, M. J. "What determines individual trade-policy preferences?". Journal of International Economics, vol. 54, nº 2, p. 267-292, 2001.

SPILKER, G.; BernAUER, T.; UMAÑA, V. "Selecting partner countries for preferential trade agreements: experimental evidence from Costa Rica, Nicaragua, and Vietnam". International Studies Quarterly, vol. 60, n$^{\circ} 4$, p. 706-718, 2016.

"What kinds of trade liberalization agreements do people in developing countries want?". International Interactions, vol. 44, no 3, p. 510-536, 2018.

TAVAKol, M.; DENnICK, R. "Making sense of Cronbach's alpha". International Journal of Medical Education, vol. 2, p. 53-55, 2011.

Zeller, R. A.; Carmines, E. G. Measurement in the social sciences: the link between theory and data. [s.l.] CUP Archive, 1980.

\section{Apêndice A - Outros resultados}

Tabela A1

Resultados completos dos modelos estimados com OLS para toda a amostra, para os não informados ou não interessados (PDD) e para os informados e interessados (PII)

\begin{tabular}{|c|c|c|c|c|c|c|c|c|c|c|c|c|}
\hline & (1) & (2) & (3) & (4) & (5) & $(6)$ & $(7)$ & (8) & (9) & (10) & $(\mathbf{1 1})$ & $(12)$ \\
\hline & ALC-vida & $\begin{array}{l}\text { ALC-vida } \\
\text { (PDD) }\end{array}$ & $\begin{array}{l}\text { ALC-vida } \\
\text { (PII) }\end{array}$ & ALC-I & $\begin{array}{l}\text { ALC-I } \\
\text { (PDD) }\end{array}$ & $\begin{array}{l}\text { ALC-I } \\
\text { (PII) }\end{array}$ & AG-vida & $\begin{array}{l}\text { AG-vida } \\
\text { (PDD) }\end{array}$ & $\begin{array}{l}\text { AG-vida } \\
\text { (PII) }\end{array}$ & AG-I & $\begin{array}{c}\text { AG-I } \\
\text { (PDD) }\end{array}$ & $\begin{array}{l}\text { AG-I } \\
\text { (PII) }\end{array}$ \\
\hline IPI $(1-P I I)$ & $\begin{array}{c}0.127 \\
(0.049)^{*}\end{array}$ & & & $\begin{array}{c}0.127 \\
(0.201)\end{array}$ & & & $\begin{array}{c}0.060 \\
(0.053)\end{array}$ & & & $\begin{array}{c}0.420 \\
(0.284)\end{array}$ & & \\
\hline \multicolumn{13}{|c|}{ Idade (0: 16 a 29 anos) } \\
\hline $\begin{array}{l}\text { De } 30 \text { a } 39 \\
\text { anos }\end{array}$ & $\begin{array}{c}0.023 \\
(0.055)\end{array}$ & $\begin{array}{c}-0.021 \\
(0.066)\end{array}$ & $\begin{array}{c}0.156 \\
(0.100)\end{array}$ & $\begin{array}{c}0.135 \\
(0.224) \\
\end{array}$ & $\begin{array}{c}-0.074 \\
(0.258)\end{array}$ & $\begin{array}{c}0.784 \\
(0.458) \S\end{array}$ & $\begin{array}{c}0.002 \\
(0.059)\end{array}$ & $\begin{array}{c}-0.016 \\
(0.070)\end{array}$ & $\begin{array}{c}0.054 \\
(0.109)\end{array}$ & $\begin{array}{c}0.436 \\
(0.317) \\
\end{array}$ & $\begin{array}{c}0.566 \\
(0.375)\end{array}$ & $\begin{array}{c}0.062 \\
(0.604)\end{array}$ \\
\hline $\begin{array}{l}\text { De } 40 \text { a } 49 \\
\text { anos }\end{array}$ & $\begin{array}{c}0.036 \\
(0.059)\end{array}$ & $\begin{array}{c}0.035 \\
(0.071)\end{array}$ & $\begin{array}{c}0.064 \\
(0.111)\end{array}$ & $\begin{array}{c}0.285 \\
(0.241)\end{array}$ & $\begin{array}{c}0.254 \\
(0.277)\end{array}$ & $\begin{array}{c}0.510 \\
(0.508)\end{array}$ & $\begin{array}{c}-0.002 \\
(0.064)\end{array}$ & $\begin{array}{c}0.021 \\
(0.075)\end{array}$ & $\begin{array}{l}-0.075 \\
(0.121)\end{array}$ & $\begin{array}{c}0.597 \\
(0.341) \\
\S\end{array}$ & $\begin{array}{c}0.722 \\
(0.402) \S\end{array}$ & $\begin{array}{c}0.040 \\
(0.671)\end{array}$ \\
\hline $\begin{array}{l}\text { De } 50 \text { a } 59 \\
\text { anos }\end{array}$ & $\begin{array}{c}-0.018 \\
(0.068)\end{array}$ & $\begin{array}{c}-0.038 \\
(0.083)\end{array}$ & $\begin{array}{c}0.046 \\
(0.115)\end{array}$ & $\begin{array}{c}0.429 \\
(0.275)\end{array}$ & $\begin{array}{c}0.237 \\
(0.327)\end{array}$ & $\begin{array}{c}0.906 \\
(0.528) \S\end{array}$ & $\begin{array}{c}-0.075 \\
(0.073)\end{array}$ & $\begin{array}{c}-0.082 \\
(0.089)\end{array}$ & $\begin{array}{c}-0.130 \\
(0.126)\end{array}$ & $\begin{array}{c}0.505 \\
(0.389)\end{array}$ & $\begin{array}{c}0.430 \\
(0.474)\end{array}$ & $\begin{array}{c}0.204 \\
(0.697)\end{array}$ \\
\hline $\begin{array}{l}\text { Mais de } 60 \\
\text { anos }\end{array}$ & $\begin{array}{c}-0.140 \\
(0.075) \S\end{array}$ & $\begin{array}{c}-0.166 \\
(0.088) \S\end{array}$ & $\begin{array}{l}-0.060 \\
(0.144)\end{array}$ & $\begin{array}{c}-0.359 \\
(0.303)\end{array}$ & $\begin{array}{c}-0.703 \\
(0.344)^{*}\end{array}$ & $\begin{array}{c}0.912 \\
(0.657)\end{array}$ & $\begin{array}{c}-0.295 \\
(0.080)^{*} \\
* *\end{array}$ & $\begin{array}{c}-0.299 \\
(0.094)^{*} \\
*\end{array}$ & $\begin{array}{c}-0.323 \\
(0.157)^{*}\end{array}$ & $\begin{array}{l}-0.617 \\
(0.430)\end{array}$ & $\begin{array}{c}-0.584 \\
(0.500)\end{array}$ & $\begin{array}{c}-0.840 \\
(0.868)\end{array}$ \\
\hline \multicolumn{13}{|c|}{ Escolaridade (0: Até $5^{\circ}$ ano Ensino Fundamental) } \\
\hline $\begin{array}{l}\text { Ens. Fund. } \\
\text { (do } 6^{\circ} \text { ao } \\
9^{\circ} \text { ano) }\end{array}$ & $\begin{array}{c}0.027 \\
(0.064)\end{array}$ & $\begin{array}{c}0.024 \\
(0.070)\end{array}$ & $\begin{array}{c}0.005 \\
(0.206)\end{array}$ & $\begin{array}{c}-0.296 \\
(0.260)\end{array}$ & $\begin{array}{l}-0.377 \\
(0.275)\end{array}$ & $\begin{array}{l}-0.266 \\
(0.942)\end{array}$ & $\begin{array}{c}-0.032 \\
(0.069)\end{array}$ & $\begin{array}{l}-0.038 \\
(0.075)\end{array}$ & $\begin{array}{c}0.105 \\
(0.225)\end{array}$ & $\begin{array}{l}-0.059 \\
(0.369)\end{array}$ & $\begin{array}{l}-0.167 \\
(0.400)\end{array}$ & $\begin{array}{c}0.477 \\
(1.243)\end{array}$ \\
\hline Superior & 0.074 & 0.065 & 0.120 & -0.826 & -1.011 & -0.117 & 0.158 & 0.082 & 0.348 & 0.846 & 0.801 & 0.518 \\
\hline
\end{tabular}




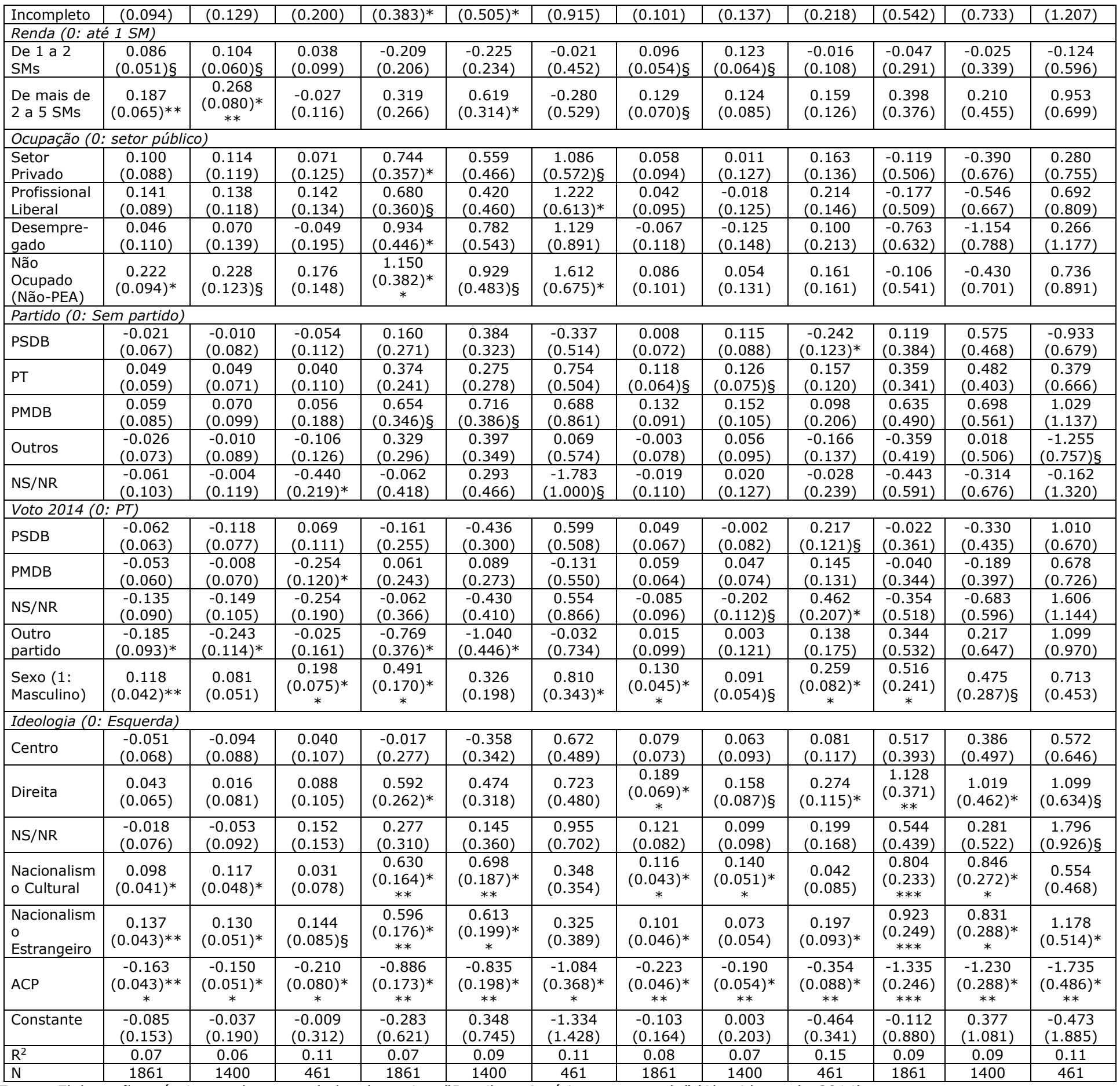

Fonte: Elaboração própria com base em dados do projeto "Brasil, as Américas e o mundo" (Almeida et al., 2014).

Erros-padrão entre parênteses. § p. <0.1;* p. <0.05;**p. <0.01;***p. <0.001. 
Tabela A2

Resultados completos dos modelos estimados com OLS e OLOGIT para toda a amostra - Variáveis dependentes de autointeresse

\begin{tabular}{|c|c|c|c|c|}
\hline & $(1)$ & (2) & (3) & (4) \\
\hline & OLS & OLOGIT & OLS & OLOGIT \\
\hline & \multicolumn{2}{|c|}{ ALC-vida } & \multicolumn{2}{|c|}{ AG-vida } \\
\hline IPI (1: PII; 0: PDD) & $\begin{array}{c}0.127 \\
(0.049) *\end{array}$ & $\begin{array}{c}0.382 \\
(0.138)^{* *}\end{array}$ & $\begin{array}{l}0.060 \\
(0.053)\end{array}$ & $\begin{array}{c}0.087 \\
(0.116)\end{array}$ \\
\hline \multicolumn{5}{|l|}{ Idade (0: 16 a 29 anos) } \\
\hline 30 a 39 anos & $\begin{array}{l}0.023 \\
(0.055)\end{array}$ & $\begin{array}{l}0.075 \\
(0.148)\end{array}$ & $\begin{array}{c}0.002 \\
(0.059)\end{array}$ & $\begin{array}{c}0.064 \\
(0.130)\end{array}$ \\
\hline 40 a 49 anos & $\begin{array}{l}0.036 \\
(0.059)\end{array}$ & $\begin{array}{c}0.054 \\
(0.156)\end{array}$ & $\begin{array}{l}-0.002 \\
(0.064)\end{array}$ & $\begin{array}{c}0.082 \\
(0.141)\end{array}$ \\
\hline 50 a 59 anos & $\begin{array}{l}-0.018 \\
(0.068)\end{array}$ & $\begin{array}{l}-0.041 \\
(0.179)\end{array}$ & $\begin{array}{l}-0.075 \\
(0.073) \\
\end{array}$ & $\begin{array}{l}-0.095 \\
(0.160) \\
\end{array}$ \\
\hline Mais de 60 anos & $\begin{array}{l}-0.140 \\
(0.075) \S\end{array}$ & $\begin{array}{l}-0.369 \\
(0.192) \S\end{array}$ & $\begin{array}{c}-0.295 \\
(0.080) * * *\end{array}$ & $\begin{array}{c}-0.573 \\
(0.173) * * *\end{array}$ \\
\hline \multicolumn{5}{|l|}{$\begin{array}{l}\text { Escolaridade (0: Até } 5^{\circ} \text { ano do } \\
\text { Ensino Fundamental) }\end{array}$} \\
\hline $\begin{array}{l}\text { Ensino Fundamental ( } 6^{\circ} \text { ao } 9^{\circ} \\
\text { ano) }\end{array}$ & $\begin{array}{c}0.027 \\
(0.064)\end{array}$ & $\begin{array}{c}0.070 \\
(0.163)\end{array}$ & $\begin{array}{l}-0.032 \\
(0.069)\end{array}$ & $\begin{array}{l}-0.065 \\
(0.149)\end{array}$ \\
\hline Ensino Médio & $\begin{array}{c}0.036 \\
(0.061) \\
\end{array}$ & $\begin{array}{c}0.103 \\
(0.157) \\
\end{array}$ & $\begin{array}{c}0.079 \\
(0.066) \\
\end{array}$ & $\begin{array}{c}0.200 \\
(0.144) \\
\end{array}$ \\
\hline Superior Incompleto & $\begin{array}{c}0.074 \\
(0.094)\end{array}$ & $\begin{array}{c}0.179 \\
(0.253)\end{array}$ & $\begin{array}{c}0.158 \\
(0.101)\end{array}$ & $\begin{array}{c}0.431 \\
(0.224) \S\end{array}$ \\
\hline Superior Completo & $\begin{array}{c}0.168 \\
(0.096) \S\end{array}$ & $\begin{array}{c}0.436 \\
(0.262) \S \\
\end{array}$ & $\begin{array}{c}0.114 \\
(0.103) \\
\end{array}$ & $\begin{array}{c}0.359 \\
(0.227) \\
\end{array}$ \\
\hline \multicolumn{5}{|l|}{ Renda (0: até 1 SM) } \\
\hline De 1 a 2 SMs (salários mínimos) & $\begin{array}{c}0.086 \\
(0.051) \S \\
\end{array}$ & $\begin{array}{c}0.208 \\
(0.132) \\
\end{array}$ & $\begin{array}{c}0.096 \\
(0.054) \S \\
\end{array}$ & $\begin{array}{c}0.149 \\
(0.117) \\
\end{array}$ \\
\hline De mais de 2 a 5 SMs & $\begin{array}{c}0.187 \\
(0.065)^{* *}\end{array}$ & $\begin{array}{c}0.499 \\
(0.180) * *\end{array}$ & $\begin{array}{c}0.129 \\
(0.070) \S\end{array}$ & $\begin{array}{c}0.263 \\
(0.155) \S \\
\end{array}$ \\
\hline Mais de 5 SMs & $\begin{array}{c}0.068 \\
(0.112) \\
\end{array}$ & $\begin{array}{c}0.180 \\
(0.313) \\
\end{array}$ & $\begin{array}{c}0.356 \\
(0.120)^{* *} \\
\end{array}$ & $\begin{array}{c}0.840 \\
(0.266)^{* *} \\
\end{array}$ \\
\hline \multicolumn{5}{|l|}{ Ocupação (0: setor público) } \\
\hline Setor Privado & $\begin{array}{c}0.100 \\
(0.088)\end{array}$ & $\begin{array}{c}0.279 \\
(0.234) \\
\end{array}$ & $\begin{array}{c}0.058 \\
(0.094) \\
\end{array}$ & $\begin{array}{c}0.222 \\
(0.206) \\
\end{array}$ \\
\hline Profissional Liberal & $\begin{array}{c}0.141 \\
(0.089) \\
\end{array}$ & $\begin{array}{c}0.432 \\
(0.236) \S \\
\end{array}$ & $\begin{array}{c}0.042 \\
(0.095) \\
\end{array}$ & $\begin{array}{c}0.157 \\
(0.207) \\
\end{array}$ \\
\hline Desempregado & $\begin{array}{c}0.046 \\
-0.110 \\
\end{array}$ & $\begin{array}{c}0.152 \\
-0.283 \\
\end{array}$ & $\begin{array}{l}-0.067 \\
-0.118 \\
\end{array}$ & $\begin{array}{l}-0.077 \\
-0.258 \\
\end{array}$ \\
\hline Não Ocupado (Não-PEA) & $\begin{array}{c}0.222 \\
(0.094)^{*}\end{array}$ & $\begin{array}{c}0.609 \\
(0.249) *\end{array}$ & $\begin{array}{c}0.086 \\
(0.101)\end{array}$ & $\begin{array}{c}0.251 \\
(0.221)\end{array}$ \\
\hline \multicolumn{5}{|l|}{ Partido (0: Sem partido) } \\
\hline PSDB & $\begin{array}{l}-0.021 \\
(0.067)\end{array}$ & $\begin{array}{l}-0.020 \\
(0.175)\end{array}$ & $\begin{array}{c}0.008 \\
(0.072)\end{array}$ & $\begin{array}{c}0.075 \\
(0.155)\end{array}$ \\
\hline PT & $\begin{array}{c}0.049 \\
(0.059)\end{array}$ & $\begin{array}{c}0.156 \\
(0.154)\end{array}$ & $\begin{array}{c}0.118 \\
(0.064) \S\end{array}$ & $\begin{array}{c}0.286 \\
(0.136) *\end{array}$ \\
\hline PMDB & $\begin{array}{c}0.059 \\
(0.085) \\
\end{array}$ & $\begin{array}{c}0.187 \\
(0.223) \\
\end{array}$ & $\begin{array}{c}0.132 \\
(0.091) \\
\end{array}$ & $\begin{array}{c}0.320 \\
(0.197) \\
\end{array}$ \\
\hline Outros & $\begin{array}{c}-0.026 \\
(0.073)\end{array}$ & $\begin{array}{c}-0.012 \\
(0.190) \\
\end{array}$ & $\begin{array}{c}-0.003 \\
(0.078) \\
\end{array}$ & $\begin{array}{c}0.013 \\
(0.169) \\
\end{array}$ \\
\hline Não Soube /Não Respondeu & $\begin{array}{c}-0.061 \\
(0.103)\end{array}$ & $\begin{array}{c}-0.152 \\
(0.252)\end{array}$ & $\begin{array}{c}-0.019 \\
(0.110)\end{array}$ & $\begin{array}{c}-0.049 \\
(0.237)\end{array}$ \\
\hline
\end{tabular}


FLÁVIO PINHEIRO; IVAN FILIPE FERNANDES; MARIA HERMINIA TAVARES DE ALMEIDA

\begin{tabular}{|c|c|c|c|c|}
\hline Voto $2014(0: P T)$ & & & & \\
\hline PSDB & $\begin{array}{l}-0.062 \\
(0.063)\end{array}$ & $\begin{array}{l}-0.165 \\
(0.166)\end{array}$ & $\begin{array}{c}0.049 \\
(0.067)\end{array}$ & $\begin{array}{c}0.087 \\
(0.146)\end{array}$ \\
\hline PMDB & $\begin{array}{l}-0.053 \\
(0.060)\end{array}$ & $\begin{array}{l}-0.111 \\
(0.156)\end{array}$ & $\begin{array}{c}0.059 \\
(0.064)\end{array}$ & $\begin{array}{c}0.115 \\
(0.138)\end{array}$ \\
\hline Não Soube /Não Respondeu & $\begin{array}{l}-0.135 \\
(0.090)\end{array}$ & $\begin{array}{l}-0.285 \\
(0.223)\end{array}$ & $\begin{array}{l}-0.085 \\
(0.096)\end{array}$ & $\begin{array}{l}-0.158 \\
(0.209)\end{array}$ \\
\hline Outro partido & $\begin{array}{c}-0.185 \\
(0.093) *\end{array}$ & $\begin{array}{c}-0.454 \\
(0.238) \S\end{array}$ & $\begin{array}{c}0.015 \\
(0.099)\end{array}$ & $\begin{array}{c}0.058 \\
(0.219)\end{array}$ \\
\hline Sexo (1: Masculino; 0:Feminino) & $\begin{array}{c}0.118 \\
(0.042)^{* *}\end{array}$ & $\begin{array}{c}0.334 \\
(0.110) * *\end{array}$ & $\begin{array}{c}0.130 \\
(0.045) * *\end{array}$ & $\begin{array}{c}0.336 \\
(0.098)^{* * *}\end{array}$ \\
\hline \multicolumn{5}{|l|}{ Ideologia (0: Esquerda) } \\
\hline Centro & $\begin{array}{l}-0.051 \\
(0.068)\end{array}$ & $\begin{array}{l}-0.122 \\
(0.183)\end{array}$ & $\begin{array}{l}0.079 \\
(0.073)\end{array}$ & $\begin{array}{c}0.137 \\
(0.161)\end{array}$ \\
\hline Direita & $\begin{array}{c}0.043 \\
(0.065) \\
\end{array}$ & $\begin{array}{c}0.109 \\
(0.174)\end{array}$ & $\begin{array}{c}0.189 \\
(0.069) * *\end{array}$ & $\begin{array}{c}0.450 \\
(0.153) * * \\
\end{array}$ \\
\hline Não Soube /Não Respondeu & $\begin{array}{l}-0.018 \\
(0.076) \\
\end{array}$ & $\begin{array}{l}-0.089 \\
(0.198) \\
\end{array}$ & $\begin{array}{c}0.121 \\
(0.082) \\
\end{array}$ & $\begin{array}{c}0.248 \\
(0.177) \\
\end{array}$ \\
\hline Nacionalismo Cultural & $\begin{array}{c}0.098 \\
(0.041)^{*}\end{array}$ & $\begin{array}{c}0.253 \\
(0.106)^{*} \\
\end{array}$ & $\begin{array}{c}0.116 \\
(0.043)^{* *} \\
\end{array}$ & $\begin{array}{c}0.295 \\
(0.094)^{* *} \\
\end{array}$ \\
\hline $\begin{array}{l}\text { Nacionalismo em relação ao } \\
\text { Estrangeiro }\end{array}$ & $\begin{array}{c}0.137 \\
(0.043) * *\end{array}$ & $\begin{array}{c}0.350 \\
(0.110) * *\end{array}$ & $\begin{array}{c}0.101 \\
(0.046)^{*}\end{array}$ & $\begin{array}{c}0.211 \\
(0.100)^{*}\end{array}$ \\
\hline $\mathrm{ACP}$ & $\begin{array}{c}-0.163 \\
(0.043)^{* * *}\end{array}$ & $\begin{array}{c}-0.401 \\
(0.110) * * *\end{array}$ & $\begin{array}{c}-0.223 \\
(0.046) * * *\end{array}$ & $\begin{array}{c}-0.485 \\
(0.100)^{* * *}\end{array}$ \\
\hline $\begin{array}{l}\text { Constante para colunas } 1 \text { e } 3 \text { e } \\
\text { cut } 1 \text { para colunas } 2 \text { e } 4\end{array}$ & $\begin{array}{l}-0.085 \\
(0.153) \\
\end{array}$ & $\begin{array}{c}0.117 \\
(0.398) \\
\end{array}$ & $\begin{array}{c}-0.103 \\
(0.164) \\
\end{array}$ & $\begin{array}{c}-2.436 \\
(0.383)^{* * *} \\
\end{array}$ \\
\hline cut2 & & $\begin{array}{c}0.718 \\
(0.399) \S \\
\end{array}$ & & $\begin{array}{l}-0.417 \\
(0.359) \\
\end{array}$ \\
\hline cut3 & & 1861.000 & & $\begin{array}{c}1.123 \\
(0.360)^{* *} \\
\end{array}$ \\
\hline cut4 & & & & $\begin{array}{c}4.070 \\
(0.374)^{* * *} \\
\end{array}$ \\
\hline $\mathrm{N}$ & 1,861 & 1,861 & 1,861 & 1,861 \\
\hline
\end{tabular}

Fonte: Elaboração própria com base em dados do projeto "Brasil, as Américas e o mundo" (Almeida et al., 2014). Erros-padrão entre parênteses. § p. <0.1;* p. <0.05; **p. < 0.01;***p. <0.001. 
Gráfico A1

Predições do efeito do Voto nas Eleições de 2014 sobre Integração Econômica

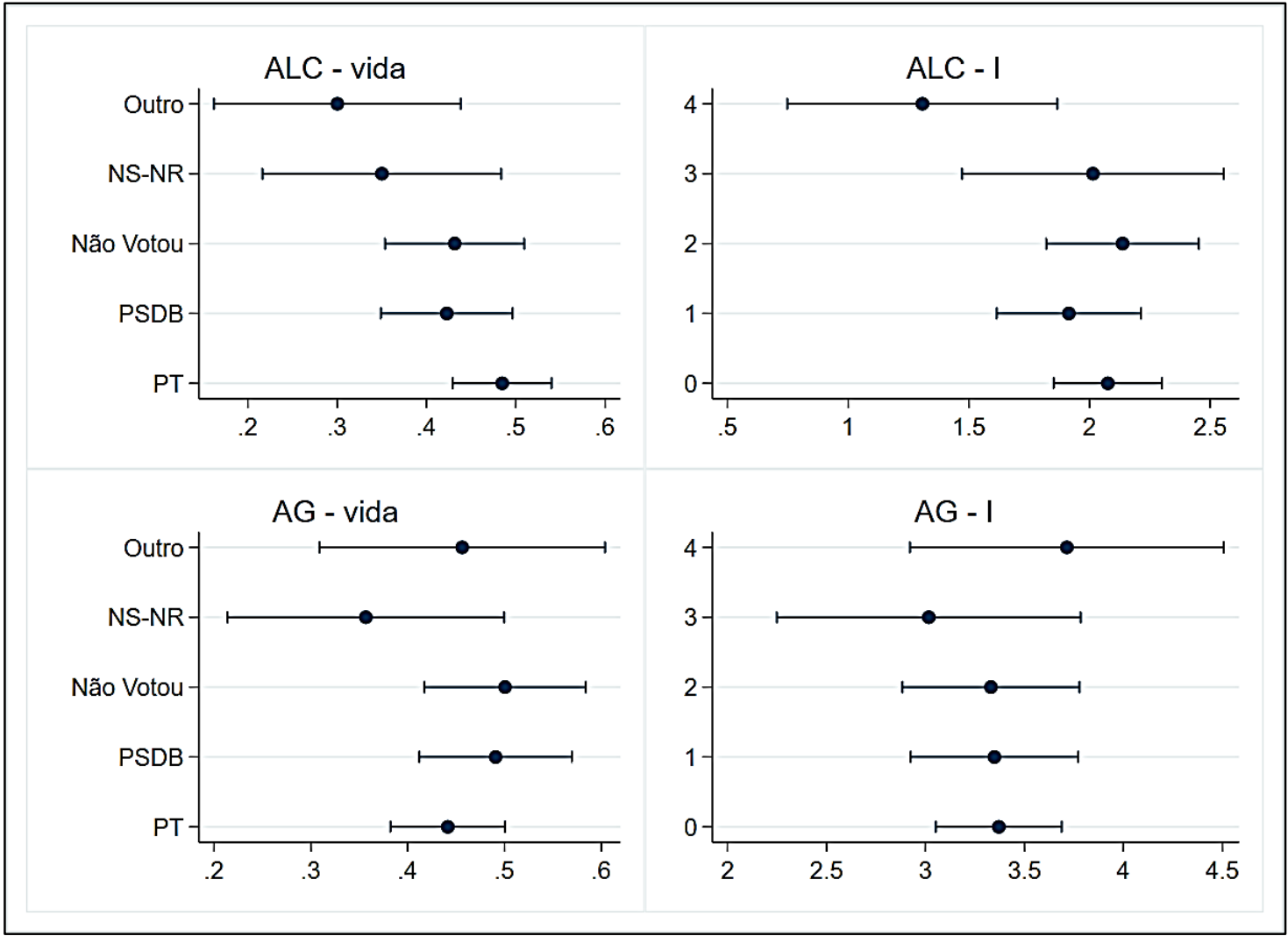

Fonte: Elaboração própria com base em dados do projeto "Brasil, as Américas e o mundo" (Almeida et al., 2014$).$ Em todos os gráficos apresentamos as predições lineares dos modelos completos estimados nas colunas (1), (4), (7) e (10) da Tabela A1. Outras variáveis foram fixadas na média. IC - 90\%. 
Gráfico A2

Predições do efeito de Identificação Partidária sobre Integração Econômica

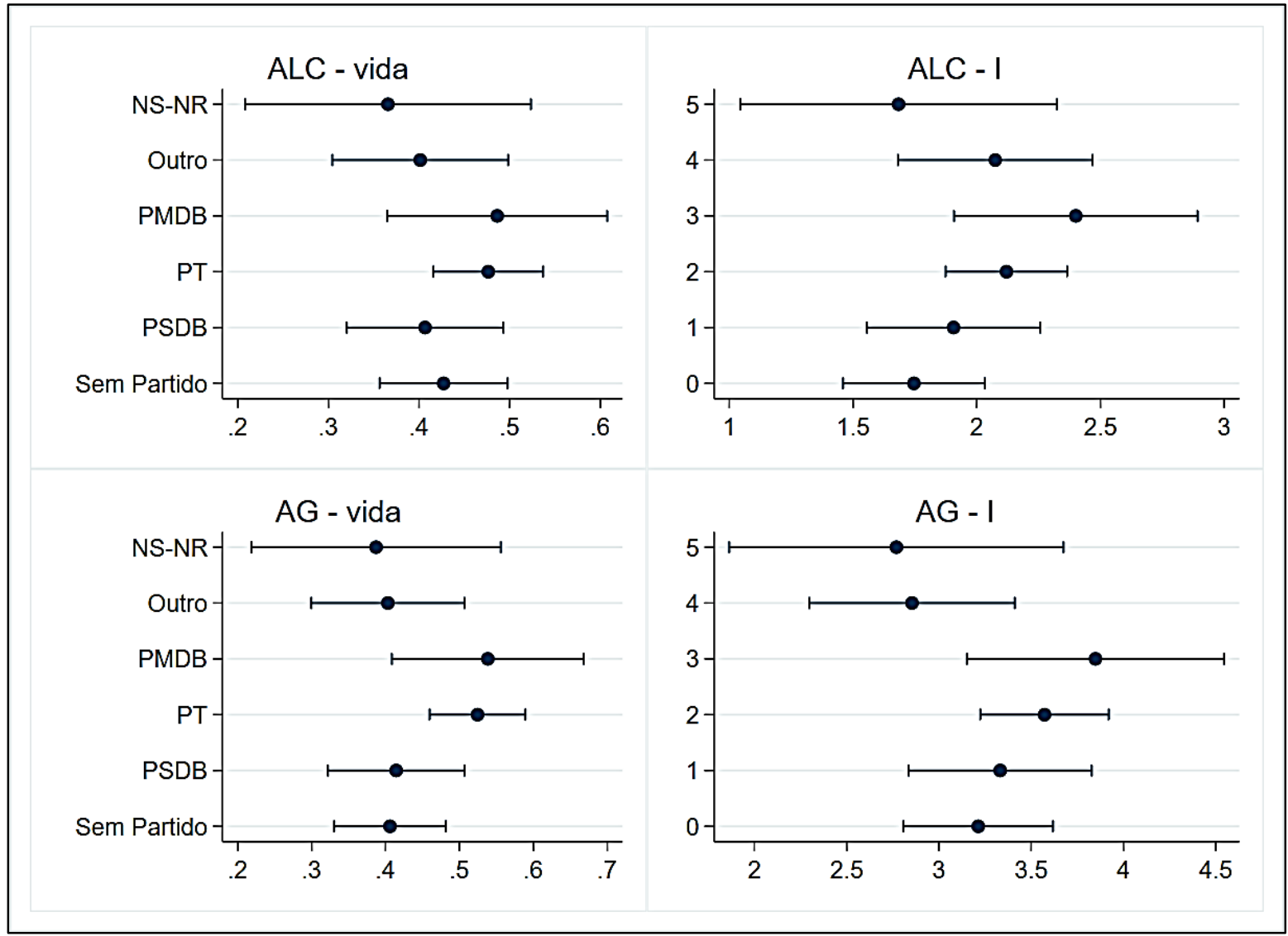

Fonte: Elaboração própria com base em dados do projeto "Brasil, as Américas e o mundo" (Almeida et al., 2014). Em todos os gráficos, apresentamos as predições lineares dos modelos completos estimados nas colunas (1), (4), (7) e (10) da Tabela A1. Outras variáveis foram fixadas na média. IC - 90\%. 
Gráfico A3

Predições do efeito de Idade sobre Integração Econômica

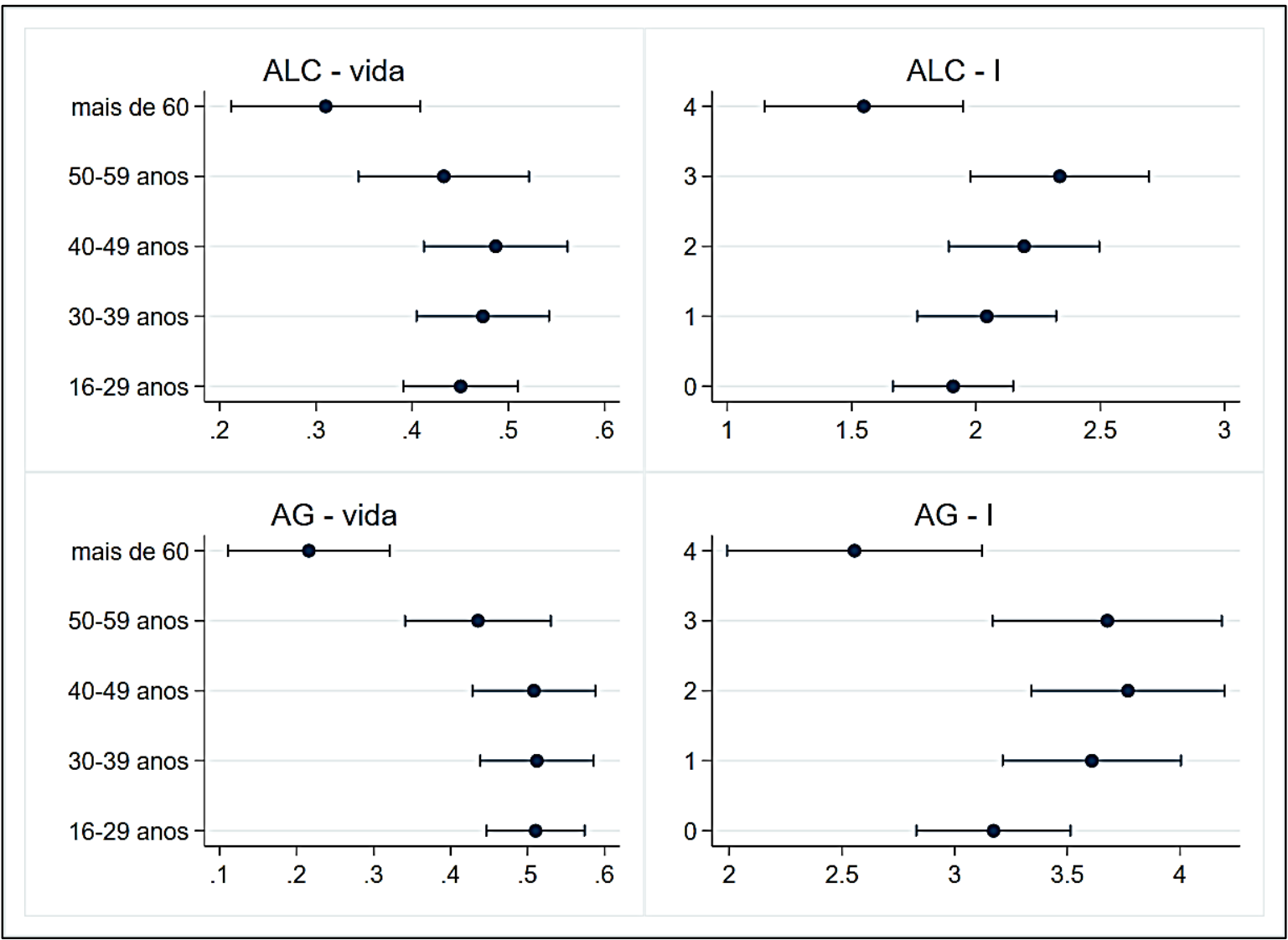

Fonte: Elaboração própria com base em dados do projeto "Brasil, as Américas e o mundo" (Almeida et al., 2014). Em todos os gráficos, apresentamos as predições lineares dos modelos completos estimados nas colunas (1), (4), (7) e (10) da Tabela A1. Outras variáveis foram fixadas na média. IC - 90\%. 


\section{Gráfico A4}

Predições do efeito de Ideologia sobre Integração Econômica

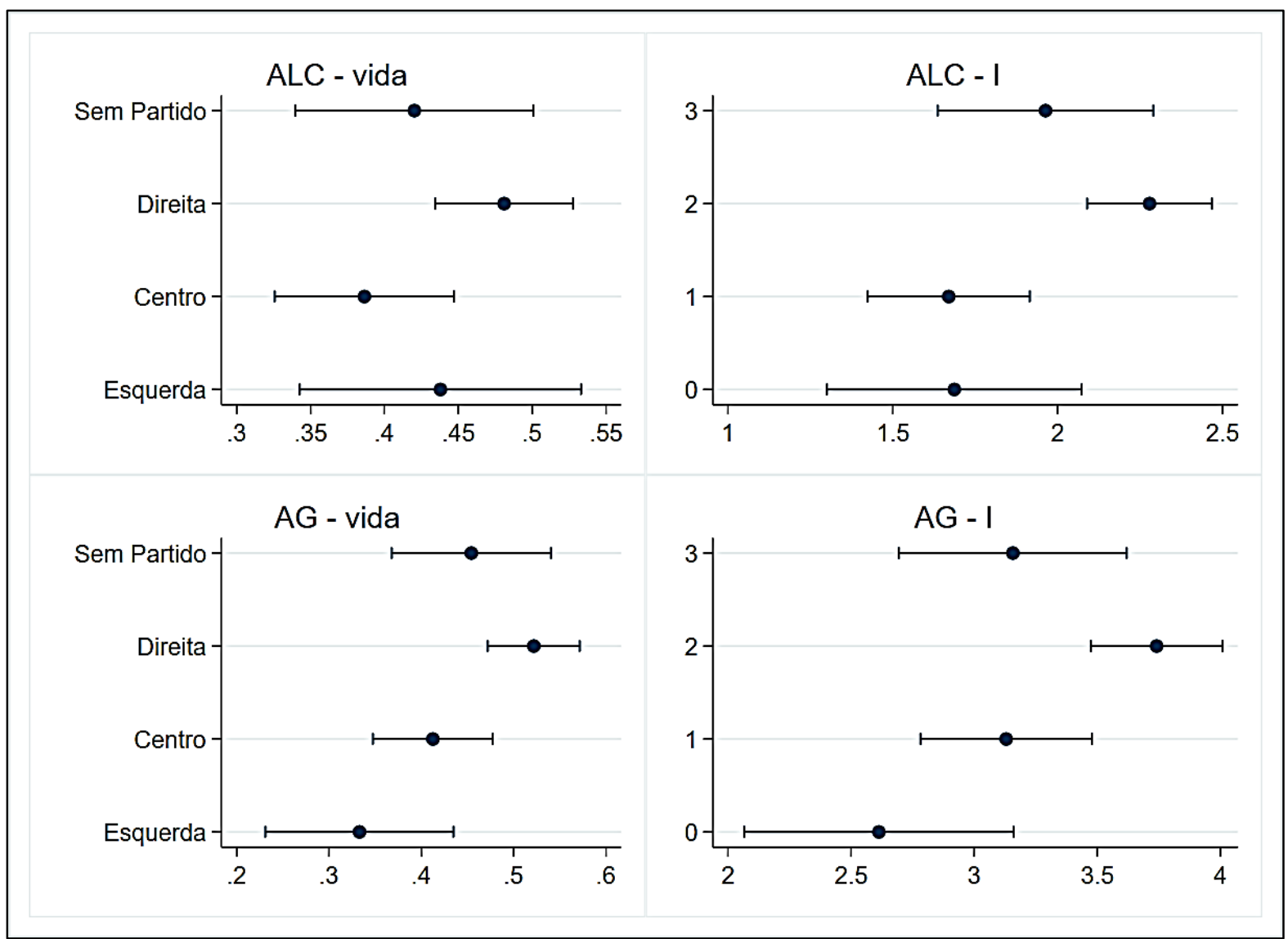

Fonte: Elaboração própria com base em dados do projeto "Brasil, as Américas e o mundo" (Almeida et al., 2014). Em todos os gráficos, apresentamos as predições lineares dos modelos completos estimados nas colunas (1), (4), (7) e (10) da Tabela A1. Outras variáveis foram fixadas na média. IC - 90\%. 
Gráfico A5

Predições do efeito de Ocupação sobre Integração Econômica

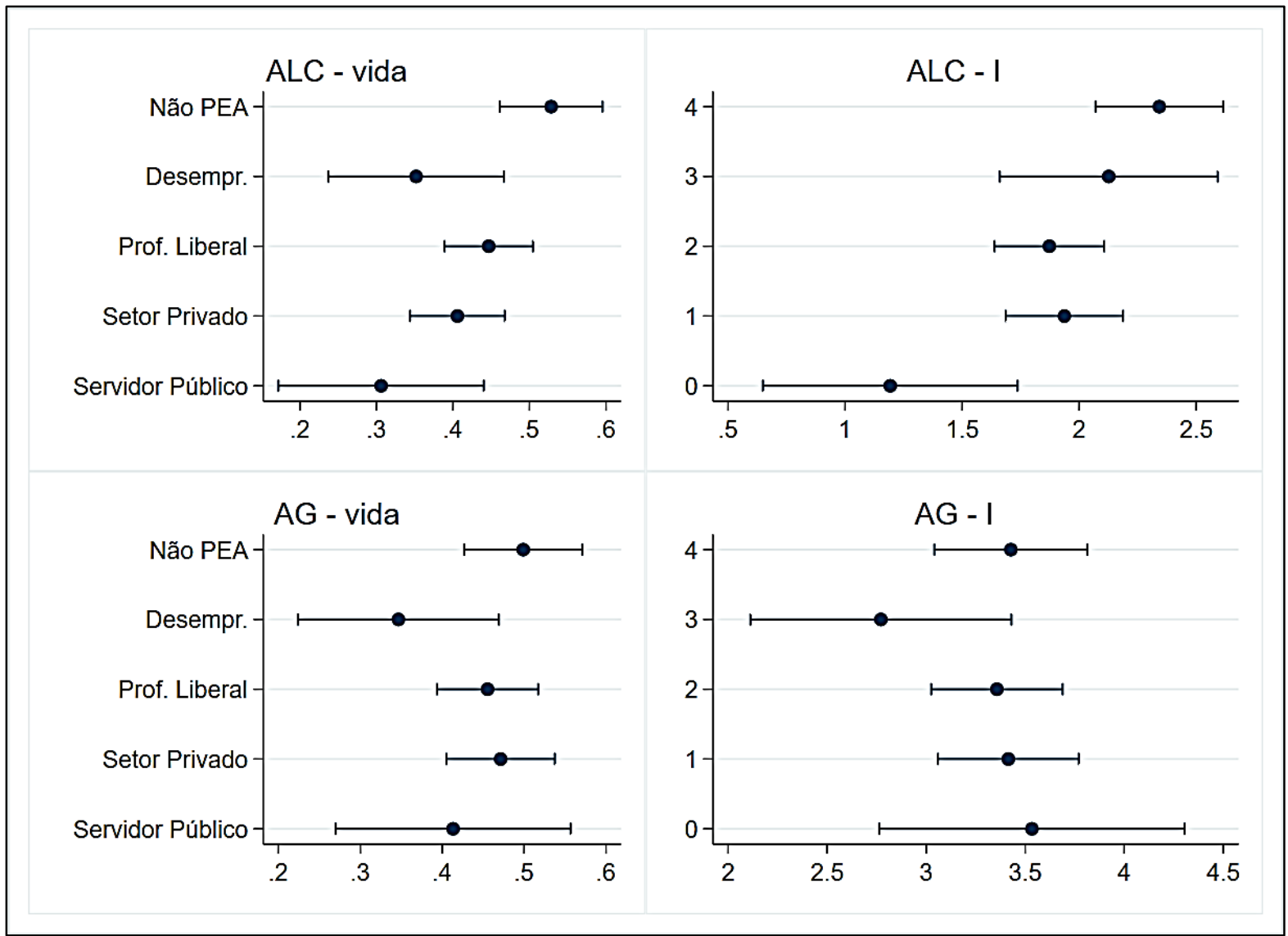

Fonte: Elaboração própria com base em dados do projeto "Brasil, as Américas e o mundo" (Almeida et al., 2014). Em todos os gráficos, apresentamos as predições lineares dos modelos completos estimados nas colunas (1), (4), (7) e (10) da Tabela A1. Outras variáveis foram fixadas na média. IC - 90\%. 


\section{Gráfico A6 \\ Predições do efeito de Educação e Renda sobre o apoio à Integração Econômica na dimensão Meio Ambiente}

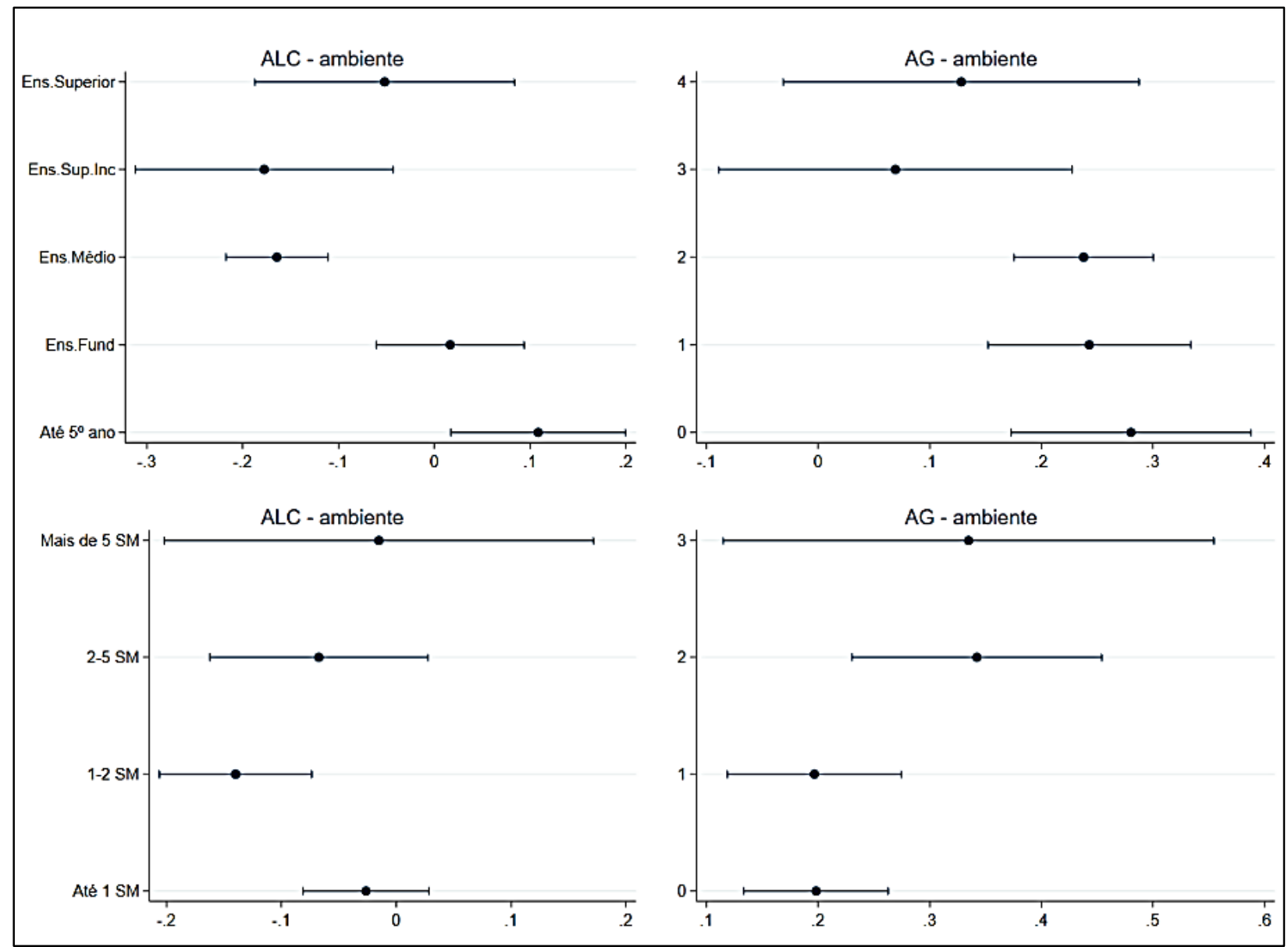

Fonte: Elaboração própria com base em dados do projeto "Brasil, as Américas e o mundo" (Almeida et al., 2014).

Em todos os gráficos, apresentamos as predições lineares dos modelos completos estimados tendo como variável dependente apenas a pergunta sobre os efeitos do livre comércio e da globalização sobre o meio ambiente. Outras variáveis foram fixadas na média. IC - $90 \%$.

\section{Apêndice B}

\section{Confiabilidade e validade das escalas de globalização e livre comércio}

Um elemento importante do presente artigo é a qualidade das escalas utilizadas para mensurar as atitudes dos indivíduos sobre a globalização e o livre comércio. Para isso, fizemos alguns testes para verificar a confiabilidade e validade dessas escalas. Adotamos procedimentos estatísticos tradicionais utilizados na psicometria para a mensuração do comportamento humano: o alfa de Cronbach e o modelo de Rasch (Claro, 2015) 
O procedimento de verificação da consistência entre os itens de uma escala de mensuração é o alfa de Cronbach. Quando os itens correlacionados medem comportamentos que estão associados, pode-se dizer que há consistência entre eles na escala. Itens que medem coisas pouco ou nada correlacionadas com o restante dos itens da escala diminuem o coeficiente alfa de Cronbach - e no resultado da análise é possível verificar quais são eles -, o que pode sugerir sua remoção da escala, a fim de obter uma melhor consistência interna (Zeller e Carmines, 1980).

Os índices de consistência interna variam teoricamente entre 0,00 (nenhuma covariação) e 1,00 (perfeita covariação); portanto, quanto mais alto o valor do coeficiente de consistência interna, mais consistente é a medida (Polit e Beck, 2018). Embora existam diversas críticas à mensuração da consistência interna por esse método, a medida é francamente utilizada, sobretudo nas áreas de saúde e psicologia, uma vez que facilmente aponta itens divergentes do restante da escala (Ong e Dulmen, 2006).

Para mensurar a validade da escala, isto é, se ela mede aquilo que deveria medir, optamos pelo tradicional modelo de Rasch (Pereira, 2010). Idealizado para uso na área da educação e da avaliação de conhecimento baseado no paradigma da Teoria da Resposta ao Item, o modelo de Rasch leva em conta a análise tanto da dificuldade de responder ao item quanto da habilidade do sujeito da pesquisa.

Para mensurar as propriedades do instrumento utilizando o modelo de Rasch, tem-se como variável dependente a probabilidade de acerto de um item para cada pessoa. $\mathrm{O}$ acerto equivale a responder positivamente a um item de acordo com uma maior quantidade da característica (trait) que está sendo mensurada. Em nosso caso, o acerto em uma escala que mensura a propensão ao apoio à integração da economia nacional aos mercados globais é dado como uma resposta positiva (o entrevistado possui a atitude mensurada pelo item $)^{17}$. Uma pessoa mais severa - no caso, mais propensa à integração - possuirá mais respostas positivas do que uma pessoa menos severa. Dessa forma, o modelo de Rasch analisa se a escala é de fato capaz de detectar mais severidade nas pessoas mais severas e menor severidade nas pessoas menos severas.

As variáveis independentes são o traço de habilidade do sujeito $(\Phi)$ - quanto o indivíduo possui das características, no presente caso, quão mais severa é sua propensão à integração - e o nível de dificuldade do item parâmetro $(\delta)$ - a palavra mais indicada seria raridade: itens raros seriam respondidos positivamente apenas por usuários mais severos, da mesma forma que questões mais difíceis de uma prova têm respostas acertadas por indivíduos mais inteligentes (Chachamovich, 2007).

O modelo de Rasch, assim, é um método prescritivo, por meio do qual é possível verificar se a escala testada atende às condições necessárias e suficientes para a mensuração fundamental desejada. O objetivo é alcançar um bom ajuste dos dados ao modelo que, por definição, atende aos requisitos necessários para a mensuração fundamental. Assim, as escalas que atendem aos requisitos do modelo de Rasch são adequadas para a mensuração da variável latente (Boone, Staver e Yale, 2014).

Por fim, antes e após a aplicação do modelo de Rasch, foram realizadas Análises de Componente Principal para verificar se o pressuposto da unidimensionalidade exigido para a aplicação do modelo é

17 O termo acerto é bastante utilizado na Teoria de Resposta ao Item, pois muitos de seus procedimentos foram criados para a análise da qualidade de testes educacionais. 
atendida pelos dados. Unidimensionalidade é a avaliação, pelo conjunto de itens, de uma única dimensão latente. Para tal, analisamos em um primeiro momento os escores brutos das escalas para verificar a existência de uma variável latente mensurada pela mesma e, em seguida, os resíduos do modelo de Rasch, a fim de verificar se existe alguma outra variável secundária após a remoção de variância do fator latente.

Resultados sobre confiabilidade (alfa de Cronbach) e validade (modelo de Rasch)

Foram entrevistados 1.881 sujeitos. Para a análise dos dados das escalas de globalização e livre comércio não houve respostas missings. As respostas Não Sei e Não Quero Responder foram consideradas neutras. Como pode ser observado na Tabela B1, o índice de consistência interna das duas escalas é superior a 0,7 , podendo ambas serem consideradas confiáveis. Por meio de análise item a item, verificou-se que não há nenhum item a ser eliminado que aumentaria o coeficiente alfa da escala caso fosse excluído. Dessa forma, todos os itens são adequados para as escalas. Alguns autores indicam que o valor desejável do alfa de Cronbach deve estar entre 0,7 e 0,9. Escalas com alfa inferior a 0,7 são inconsistentes e escalas com alfa superior a 0,9 são redundantes, indicando que alguns itens são desnecessários e poderiam ser retirados em busca de uma escala mais parcimoniosa (Claro, 2015; Tavakol e Dennick, 2011).

Tabela B1

Análise descritiva e alfa de Cronbach das escalas de globalização e livre comércio

\begin{tabular}{|c|c|c|c|c|c|c|}
\hline Escala & Média & Variância & $\begin{array}{l}\text { Desvio- } \\
\text { padrão }\end{array}$ & No itens & Alfa de Cronbach & IC $95 \%$ \\
\hline LC & 2 & 11,47 & 3.39 & 6 & $0,737 c$ & $0,718-0,755$ \\
\hline GLOB & 3,85 & 28,2 & 5.32 & 8 & $0,864 c$ & $0,854-0,873$ \\
\hline \multicolumn{7}{|c|}{ Análise item a item } \\
\hline \multicolumn{3}{|c|}{ Livre comércio } & \multicolumn{4}{|c|}{ Globalização } \\
\hline Item & $\begin{array}{l}\text { Média com } \\
\text { exclusão † }\end{array}$ & $\begin{array}{l}\text { Alfa com } \\
\text { exclusão }\end{array}$ & Item & & Média com exclusãot & Alfa com exclusão \\
\hline globeconbrasileira & 3,27 & 0,851 & Icmeioamb & nte & 2,06 & 0,726 \\
\hline globempbrasileiras & 3,22 & 0,847 & Icecobrasile & & 1,62 & 0,686 \\
\hline globconsumidores & 3,32 & 0,840 & Icvida & & 1,56 & 0,695 \\
\hline globempregos & 3,34 & 0,864 & Icempresas & rasileiras & 1,68 & 0,713 \\
\hline globambiente & 3,66 & 0,864 & Icagricultur & & 1,53 & 0,693 \\
\hline globtrabalhista & 3,45 & 0,844 & Icatrabalho & & 1,54 & 0,687 \\
\hline globvida & 3,39 & 0,84 & & & & \\
\hline globgeracoes & 3,3 & 0,841 & & & & \\
\hline
\end{tabular}

Fonte: Elaboração própria com base em dados do projeto "Brasil, as Américas e o mundo" (Almeida et al., 2014).

Nota: †Média da escala se o item for excluído. ¥Alfa de Cronbach se o item for excluído.

Para a análise do modelo de Rasch, optamos por transformar as variáveis em 0 e 1. Indicamos como 0 as respostas neutras ou negativas e como 1 as respostas positivas. Após a recategorização, procedeu-se à análise fatorial de cada escala. A análise exploratória foi feita por meio da análise de 
componentes principais com rotação varimax. Em ambos os casos, a análise fatorial exploratória indica uma solução de apenas um fator.

Modelo de Rasch: globalização

Na escala de globalização, as primeiras três unidades de variância (eigenvalues) são de 4,1, 0,8 e 0,7 , sendo o primeiro fator responsável por $51 \%$ da variância de toda a escala, o segundo por apenas $10 \%$ e o terceiro por $8 \%$, o que indica que existe uma solução de um único fator. Antes e após a rotação varimax, todos os itens apresentaram carga fatorial (loadings) superior a 0,6 com o primeiro fator. Comprovada a unidimensionalidade de cada uma das escalas, procedemos à análise com a verificação da adequabilidade dos dados ao modelo de Rasch. Apresentamos na Tabela B2 os dados da análise de Rasch por itens para a escala de globalização.

Os valores de mean square de Infit e Outfit indicam que todos os itens são aceitáveis pelo modelo de Rasch, e todos os itens estão entre 0,8 e 1,3. Os melhores níveis para a mensuração são os mais próximos de 1 . Entre 0 e 0,5 são considerados improdutivos para a mensuração, embora não a prejudiquem, e de 0,5 a 1,5 são considerados ótimos. De 1,5 a 2 são considerados improdutivos para a mensuração, embora não a prejudiquem. Caso o Infit ou o Outfit apresente valor acima de 2, considerase que o item distorce a mensuração (Boone, Staver e Yale, 2014). Nos casos em que o mean square para Infit e Outfit é superior a 2, é feita a análise do teste de aleatoriedade do mean square (ZSTD). Quando o valor do ZSTD é também superior a 2, conclui-se que o resultado não é aleatório, e o item de fato prejudica a mensuração. Nenhum item da escala de globalização possui Infit ou Outfit para o mean square acima de 2 .

Tabela B2

Análise do modelo de Rasch da escala de globalização

\begin{tabular}{|c|c|c|c|c|c|c|c|c|c|}
\hline \multicolumn{3}{|l|}{ Item } & \multicolumn{3}{|c|}{ Parâmetros } & \multicolumn{2}{|c|}{ Média } & \multicolumn{2}{|c|}{ ZSTD } \\
\hline- & $\%$ & Severidade & $\mathbf{X 2}$ & df & p-valor & Outfit & Infit & Outfit & Infit \\
\hline globambiente & 48 & 0,80 & 1620,6 & 1224 & 0,00 & 1,3 & 1,2 & 6,4 & 7,7 \\
\hline globtrabalhista & 54 & 0,33 & 1032,8 & 1224 & 1,00 & 0,8 & 0,9 & $-4,0$ & $-3,4$ \\
\hline globvida & 56 & 0,19 & 1127,3 & 1224 & 0,98 & 0,9 & 0,9 & $-2,0$ & $-2,7$ \\
\hline glogeracoes & 61 & $-0,16$ & 1050,8 & 1224 & 1,00 & 0,9 & 0,9 & $-3,3$ & $-3,2$ \\
\hline globconsumidores & 61 & $-0,18$ & 1215,7 & 1224 & 0,56 & 1,0 & 1,0 & $-0,2$ & 0,3 \\
\hline globempregos & 62 & $-0,21$ & 1032,9 & 1224 & 1,00 & 0,8 & 0,9 & $-3,6$ & $-3,5$ \\
\hline globeconbrasileira & 62 & $-0,25$ & 1324,1 & 1224 & 0,02 & 1,1 & 1,0 & 1,7 & 1,5 \\
\hline globempbrasileiras & 66 & $-0,52$ & 1216,4 & 1224 & 0,56 & 1,0 & 1,0 & $-0,1$ & 0,7 \\
\hline
\end{tabular}

Fonte: Elaboração própria com base em dados do projeto "Brasil, as Américas e o mundo" (Almeida et al., 2014).

Finalmente, a análise de componentes principais dos resíduos não apresenta indícios de que haja outra dimensão na escala, o que confirma sua unidimensionalidade, pois a variação da dimensão latente foi extraída pelo modelo de Rasch. O primeiro componente dos resíduos responde por apenas 1,42 unidade de variância, enquadrando-se no limite de 1,9 sugerido pela literatura de Rasch, seguido de outros componentes com 1,34 e 1,26 unidade de variância, cada um correspondendo, 
respectivamente, a 18\%, $17 \%$ e $16 \%$ da variância - ou seja, não existe uma dimensão a ser detectada pela análise fatorial (Humphreys e Montanelli Jr., 1975).

Modelo de Rasch: livre comércio

Na escala de livre comércio, as primeiras três unidades de variância (eigenvalues) são de 4,7, 0,81 e 0,77, sendo o primeiro fator responsável por $45 \%$ da variância de toda a escala, o segundo por apenas $14 \%$ e o terceiro por $13 \%$, o que indica que existe uma solução de um único fator para os dados. Antes e após a rotação varimax, quase todos os itens apresentaram carga fatorial (loadings) superior a 0,6 com o primeiro fator. Apenas o item livre comércio - meio ambiente apresentou fator inferior. Comprovada a unidimensionalidade de cada uma das escalas, procedemos à análise com a verificação da adequabilidade dos dados ao modelo de Rasch. Apresentamos na Tabela B3 os dados da análise de Rasch por itens para a escala de livre comércio. Os valores de mean square de Infit e Outfit indicam que todos os itens são aceitáveis pelo modelo de Rasch, pois todos estão entre 0,8 e 1,1.

Tabela B3

Análise do modelo de Rasch da escala de livre comércio

\begin{tabular}{|l|c|c|c|c|c|c|c|c|c|}
\hline & & & \multicolumn{3}{|c|}{ Parâmetros } & \multicolumn{2}{c|}{ Média } & \multicolumn{2}{c|}{ ZSTD } \\
\hline Item & $\%$ & Severidade & $\mathrm{X} 2$ & $\mathrm{df}$ & $\mathrm{p}$-valor & Outfit & Infit & Outfit & Infit \\
\hline Icmeioambiente & 39 & 1,34 & 1491,4 & 1335 & 0,00 & 1,1 & 1,1 & 2,1 & 2,9 \\
\hline $\begin{array}{l}\text { Icempresasbrasilei- } \\
\text { ras }\end{array}$ & 60 & 0,05 & 1394,1 & 1335 & 0,13 & 1,0 & 1,0 & 1,2 & 1,7 \\
\hline Icecobrasileira & 63 & $-0,13$ & 1143,6 & 1335 & 1,00 & 0,9 & 0,9 & $-3,9$ & $-3,9$ \\
\hline Icvida & 66 & $-0,36$ & 1235,1 & 1335 & 0,98 & 0,9 & 0,9 & $-1,8$ & $-2,1$ \\
\hline Icagricultura & 67 & $-0,44$ & 1159,1 & 1335 & 1,00 & 0,9 & 0,9 & $-3,1$ & $-2,2$ \\
\hline Ictrabalho & 67 & $-0,45$ & 1120,8 & 1335 & 1,00 & 0,8 & 0,9 & $-3,8$ & $-2,6$ \\
\hline
\end{tabular}

Fonte: Elaboração própria com base em dados do projeto "Brasil, as Américas e o Mundo" (Almeida et al., 2014).

Finalmente, a análise de componentes principais dos resíduos não apresenta indícios de que haja outra dimensão na escala, o que confirma sua unidimensionalidade, pois a variação da dimensão latente foi extraída pelo modelo de Rasch. O primeiro componente dos resíduos responde por apenas 1,4 unidade de variância, seguido de outros componentes com 1,3 e 1,2 unidades de variância, cada um correspondendo, respectivamente, a $23 \%, 21 \%$ e $20 \%$ da variância - ou seja, não existe uma dimensão a ser detectada pela análise fatorial.

\begin{abstract}
Money or ideology? Determinants of individual-level attitudes towards globalization and free-trade in Brazil

In this paper, we seek to explain the determinants of individual-level attitudes of Brazilians towards free-trade. We use national survey data collected by the project "O Brasil, as Américas e o mundo" and show that Brazilians support open trade. We argue that individual attitudes are guided by economic interests, ideational factors, and political values. The low exposure of the Brazilian economy to international competition seems to contribute to favorable opinions about access to imported goods.
\end{abstract}


Ideological preferences, in turn, filter these perceptions regardless of the individual's economic conditions. Overall, our results are similar to the findings of a broad literature on trade-policy preference in developed countries.

Keywords: public opinion; political behavior; globalization; international political economy; free trade preferences

\section{Resumen}

¿El bolsillo o la ideología? Determinantes de la opinión de brasileños sobre globalización y libre comercio

El artículo analiza los determinantes de las opiniones de los brasileños sobre la integración de la economía brasileña en los mercados globales, analizando los datos de encuesta, con una muestra nacional, realizada en el ámbito del proyecto "Brasil, las Américas y el mundo". Demostramos que los brasileños, en gran medida, son a favor de la apertura internacional de nuestra economía y que sus actitudes están guiadas tanto por motivaciones económicas como por ideas y valores políticos. La baja exposición de la economía brasileña a la competición externa parece contribuir a la existencia de opiniones a favor de un mayor acceso a los bienes importados. La posición ideológica, a su vez, actúa como un filtro para estas percepciones independientemente de las condiciones económicas de los individuos. Así, la evidencia indica que la posición del individuo como consumidor, su ideología política y sus puntos de vista nacionalistas influyen en sus pun-tos de vista sobre la globalización y el libre comercio. Los resultados confirman estudios previos sobre el mismo tema realizados en países en desarrollo.

Palabras clave: opinión pública; comportamiento político; globalización; comercio internacional; economía política internacional

\section{Résumé}

La poche ou l'idéologie? Déterminants de l'opinion de les brésiliens sur la mondialisation et le libreéchange

L'article traite des déterminants des opinions brésiliennes sur l'intégration de l'économie brésilienne dans les marchés mondiaux, nous analysons les données d'enquête, avec un échantillon national, réalisée dans le cadre du projet "Brésil, les Amériques et le monde". Nous montrons que les Brésiliens, dans une large mesure, sont favorables à l'ouverture internationale de notre économie et que leurs attitudes sont guidées par des motivations économiques et par des idées et des valeurs politiques. La faible exposition de l'économie brésilienne à la concurrence extérieure semble contribuer à l'existence d'opinions en faveur d'un meilleur accès aux biens importés. La position idéologique, à son tour, agit comme un filtre pour ces perceptions quelles que soient les conditions économiques des individus. Ainsi, les preuves indiquent que la position de l'individu en tant que consommateur, son idéologie politique et ses opinions nationalistes influencent ses opinions sur la mondialisation et le libre-échange. Les résultats confirment des études antérieures sur le même sujet menées dans des pays en développement.

Mots-clés: opinion publique; comportement politique; mondialisation; commerce international; économie politique internationale

Artigo submetido à publicação em 2 de março de 2020. Versão final aprovada em 3 de maio de 2021.

Opinião Pública adota a licença Creative Commons CC-BY.

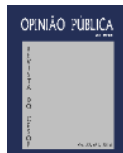

